\title{
Identification of Key Immune-Related Genes, Molecular Pathways and Immune Infiltration as Diagnostic and Therapeutic Candidate Targets for RA: an integrated bioinformatics-based analysis
}

\section{Sheng Fang}

Anhui Medical College: Anhui Medical University

Xiao Fang

Anhui Medical College: Anhui Medical University

Xin Xu

Anhui Medical College: Anhui Medical University

Lin Zhong

Anhui Medical College: Anhui Medical University

An-quan Wang

Anhui Medical College: Anhui Medical University

Wei-lu Gao

Anhui Medical College: Anhui Medical University

Zong-Sheng yin ( $\square$ anhuiyzs@outlook.com )

Anhui Medical University https://orcid.org/0000-0001-7632-5088

\section{Research Article}

Keywords: Rheumatoid arthritis, Kyoto Encyclopedia of Genes and Genomes pathway, Gene Ontology's enrichment analysis, Gene-set enrichment analysis, Hub gene, Immune infiltration, Predictive preventive personalized medicine

Posted Date: March 17th, 2021

DOI: https://doi.org/10.21203/rs.3.rs-296982/v1

License: (a) (i) This work is licensed under a Creative Commons Attribution 4.0 International License. Read Full License 


\section{Abstract \\ Relevance}

Rheumatoid arthritis (RA) is a systemic autoimmune disease with an aggressive, chronic synovial inflammation as the main pathological change. However, the specific etiology, pathogenesis, and related biomarkers in diagnosis and treatment are still not fully elucidated. This study attempts to provide new perspectives and insights into RA at the genetic, molecular, and cellular levels through the tenet of personalized medicine.

\section{Methods}

Gene expression profiles of four individual knee synovial tissues were downloaded from a comprehensive gene expression database, R language was used to screen for significantly differentially expressed genes (DEGs), Gene Ontology Enrichment Analysis, Kyoto Gene Encyclopedia, and Gene Set Enrichment Analysis were performed to analyze the biological functions and signaling pathways of these DEGs, STRING online database was used to establish protein-protein interaction networks, Cytoscape software to obtain ten hub genes, Goplot to get six inflammatory immune-related hub genes, and CIBERSORT algorithm to impute immune infiltration.

\section{Results}

Molecular pathways that play important roles in RA were obtained: Toll-like receptors, AMPK, MAPK, TNF, FoxO, TGF-beta, PI3K and NF-KB pathways, Ten hub genes: Ccr1, Ccr2, Ccr5, Ccr7, Cxcl5, Cxcl6, Cxcl13, Ccl13, Adcy2, and Pnoc. among which Adcy 2 and Pnoc have not been reported in RA studies, suggesting that they may be worthy targets for further study. It was also found that among the synoviocytes in RA, the proportions of plasma cells, CD8 T cells, follicular helper T cells, monocytes, $Y$ delta T cells, and M0 macrophages were higher, while the proportions of CD4 memory resting T cells, regulatory T cells (Tregs), activated NK cells, resting dendritic cells, M1 macrophages, eosinophils, activated mast cells, resting mast cells were lower in proportion, and each cell played an important role in RA.

\section{Conclusions}

This study may help understand the key genes, molecular pathways, the role of inflammatory immune infiltrating cells in RA's pathogenesis and provide new targets and ideas for the diagnosis and personalized treatment of RA.

\section{Introduction}

Rheumatoid arthritis (RA) is a systemic autoimmune disease characterized by chronic synovial inflammation and vascular opacification with multiple, symmetrical, aggressive inflammation, immune cell infiltration, destruction of cartilage and bone tissue, deformation of affected joints, and eventual loss of function as the main pathological changes[1-3]. Genetic susceptibility and environmental changes, inflammation, immune dysfunction, altered gene expression, and abnormal molecular signaling pathways be involved in the 
pathogenesis of RA. The synovial tissue plays the most critical role in the disease process. Many inflammatory and immune cells, such as neutrophils, macrophages, dendritic cells, T cells, and B cells, are gathered. These cells release chemokines, proteases, pro-inflammatory cytokines, and other substances that activate and regulate each other, forming a complex network. Simultaneously, these inflammatory and immune cells can lead to immune infiltration, activate the complement system, participate in antigen presentation reactions, induce abnormal activation of osteoclasts, abnormal vascular proliferation, and accelerate cartilage and bone erosion. These inflammatory immune storms lead to further development, evolution, and deterioration of the RA condition, ultimately leading to joint deformity and loss of function [4-7]. However, the specific etiology and pathogenesis are not fully clarified. Therefore, identifying key biomarkers and therapeutic targets from multiple perspectives, such as genes, signaling pathways, and immune cell infiltration, for accurate prediction, prevention, and personalized medicine (pppm) of RA is the current hot spot and development trend of RA research[8]. It also provides new ideas and methods for clinical diagnosis and personalized treatment.

Bioinformatics uses computer science to collect, process, and analyze big data obtained by gene chips and sequencing technologies. It allows us to perform large-scale screening of genetic changes in disease development at the microscopic level. It has become an effective method for studying the mechanisms of refractory diseases. Studies are increasingly using gene microarray technology to identify aberrantly expressed genes closely associated with disease pathogenesis. These genes regulate inflammatory factors, chemokines, various protein molecules, and cellular signaling pathways through transcription and translation, deriving different protein phenotypes that cause changes in normal biological functions and ultimately lead to the onset, development, and evolution of diseases[9-11]. These studies have mainly focused on tumor-related diseases[12-15]. And there are relatively few bioinformatics studies on non-tumor-related diseases. Meanwhile, due to samples' inconsistent gene expression profiles from different sequencing platforms, some bioinformatics analyses of rheumatoid arthritis are limited to one or two microarray data, or data from multiple platforms are used but not normalized. The results are more limited and less reliable, so the problem can be effectively solved by combining and normalizing multi-gene microarray data[16-19]. This study performed comprehensive bioinformatics analysis, screening, and identification of synovial tissue and infiltrating inflammatory immune cells that play a crucial role in the pathogenesis from synovitis to cartilage and bone destruction (Fig. 1). We expect to obtain more biologically significant diagnostic markers or object drug targets, providing new ideas and targets for RA's molecular mechanisms and a scientific basis and resources for effective diagnosis, prognosis assessment, and personalized treatment of RA PPPM.

\section{Materials And Methods}

\section{Merging and batch normalization of data}

We downloaded four RA synovial datasets (GSE1919, GSE55235, GSE77298, and GSE55457) from the GEO database. GSE1919[20]was based on GPL91 platforms, GSE55235[21] was based on GPL96 platforms, The GSE77298[22]data was based on GPL570 platforms,GSE55457[18]was based on GPL96 platforms. As the Normal group, we used gene expression profiling microarray of Synovial tissue from the healthy joint and expression profiling microarray of synovial tissue from rheumatoid arthritis joint as the RA group. The information regarding these datasets was shown in (Table 1). 
We annotated these four raw data files separately with the Strawberry Perl software, transformed the line names into official gene name matrix files, deleted data without gene names, and merged the data with different names for the same gene by taking the average value. After that, we use the "sva" package $[23,24]$ of $R$ language to batch normalize these four data files $[25,26]$. So that these four files were combined into one normalized gene matrix file, these data sets are shown in (Table 2).

\section{Identifying differentially expressed genes and assessing their enrichment in function and pathways}

We used the $\mathrm{R}$ language limma package to analyze the above-normalized gene data files with log 2 greater than one and p-values less than 0.05 , yielding genes that were significantly differentially expressed in the RA group [27]. These data sets are shown in (Table 3).

We performed Gene Ontology's (GO's) enrichment analysis of differentially expressed genes obtained above, using the R language clustering package to determine that these genes are enriched among the following three classifications: biological processes, cellular composition, and molecular functions [28, 29], and then deduced the signaling pathways involved in RA by KEGG enrichment analysis[30, 31].

\section{Analyzing of Gene-set enrichment}

Gene-Set Enrichment Analysis (GSEA) analyzed gene expression matrix files, which retains more information than traditional GO and KEGG enrichment analysis by analyzing collections of genes rather than focusing on individual gene expression changes, avoiding omission genes[32]. In this study, the above four gene matrix files were analyzed by the GSEA-related packages "BiocManager," “Dose," "ClusterProfiler," and "Stringi” in R language. Each analyzed gene set was executed 1000 times with enrichment score (NES) absolute value greater than one and p-value less than 0.05.[33-35].

\section{Discovering the network of protein-protein interactions}

The STRING database is an online resource applied to an organism-wide protein association network[36, 37]. It predicts protein-protein interactions and deciphers the functions between proteins by searching gene interactions. To find potential interactions between proteins in this study, we used the STRING (version 11.0) tool. The names of genes with significant expression differences obtained previously were entered, and the species was "Homo sapiens," and the highest confidence level was chosen to be 0.9. In the network, each node corresponds to a protein, and each edge represents an interaction. The thickness of the edge represents the strength of the interaction. Select the "string_interactions.tsv" file in the exported options for subsequent analysis. Then we use the R language barplot to analyze and visualize the "string_interactions.tsv" protein interactions network file.

\section{Identifying hub genes and screening for inflammation and immune-related hub genes}

Cytoscape is an excellent tool for analyzing protein interactions, and the software has many functional extension plug-ins[38, 39]. We used Cytoscape (v3.8.0) software to analyze the above-exported protein interaction network files. The Cytohubba plug-in can use various algorithms to calculate the nodes and links in 
the protein interaction network to obtain the hub genes. This study chose the MCC algorithm in the Cytohubba plug-in to obtain the top ten hub genes in the PPI network[40, 41].

We applied the GOplot package in R language, selected inflammation and immunity-related terms for gene prediction. We crossed the predicted genes with hub genes to get hub genes associated with inflammation and immunity[42-44].

\section{Assessing the profile of immune cell infiltration}

To infer the relative proportions of 22 infiltrating types of immune cells, we used the CIBERSORT algorithm, including neutrophils, eosinophils, T cells, macrophages, B cells, dendritic cells, and natural killer cells, etc. in RA synovial samples[45-47]. So we use the packages "e1071," "parallel," "preprocessCore," and "CIBERSORT.R" to get the sample's immune cell matrix. And use the barplot to show the proportion and composition of these immune cells. Then we use the R "corrplot" package to get the correlation heatmap of infiltrated immune cells. Next, We performed the heatmap mentioned above of immune cells to illustrate the various immune cells' composition in different samples. In addition, we reduced the sample dimension to perform principal component analysis (PCA) on the differences between RA samples and normal samples. Finally, To show the differences in the abundance of infiltrating immune cells between them, we used the R language' vioplot' package.

\section{Results}

\section{Identification of DEGs}

After normalization of the four merged gene matrix files, the median line of the data before normalization was fluctuating up and down, showing that the median of each sample data was in a straight line after normalization, and the boxplot showed that the data met the criteria for further study as shown in Fig. 2. The DEGs were filtered in the $\mathrm{R}$ language using the limma package, as shown in Table 3. The blue points on the volcano map's left side indicate genes with significantly down-regulated expression. The orange points on the right side indicate genes with up-regulated expression considerably. Heatmaps of the 20 DEGs with the highest and lowest gene expression rankings in RA were created using the Heatmap package in R language, as shown in Fig. 3 and Table 4.

\section{Functional analysis of DEGs}

On these DEGs, We performed GO enrichment analysis. These genes were enriched into three categories: molecular functions, cellular components, and biological processes, and the ten highest-ranked terms in each category were visualized using the GOBubble function of the R language GOplot package. They are shown in Fig. 4 (a) (b) (c) and Table 5, respectively.

The top 10 terms enriched by the molecular function are main in: immune receptor activity, chemokine activity, cytokine activity, chemokine receptor binding, cytokine binding, antigen binding, cytokine receptor activity, CXCR chemokine receptor binding, $\mathrm{C}-\mathrm{C}$ chemokine receptor activity, chemokine receptor activity.

The top 10 terms enriched by the cellular components are main in: collagen-containing extracellular matrix, immunological synapse, endocytic vesicle, coated vesicle membrane, External side of the plasma membrane, 
endocytic vesicle membrane, clathrin-coated endocytic vesicle membrane, specific granule, membrane microdomain, tertiary granule lumen, secretory granule membrane.

The top 10 terms enriched by the biological processes are main in: T cell activation and differentiation, regulation of leukocyte cell - cell adhesion, positive regulation of leukocyte activation, positive regulation of leukocyte cell - cell adhesion, lymphocyte differentiation, positive regulation of lymphocyte activation, lymphocyte chemotaxis, and proliferation, mononuclear cell proliferation, cell chemotaxis.

\section{Pathway analysis of DEGs}

On these DEGs, we performed KEGG enrichment analysis. Below are the primary signaling pathways: Cytokinecytokine receptor interaction, Chemokine signaling pathway, Rheumatoid arthritis, Hematopoietic cell lineage, Primary immunodeficiency, Viral myocarditis, Graft-versus-host disease, Osteoclast differentiation, Cell adhesion molecules, Viral protein interaction with cytokine and cytokine receptor, Leishmaniasis, NF-kappa B signaling pathway, B cell receptor signaling pathway, Intestinal immune network for IgA production, Th17 cell differentiation, Staphylococcus aureus infection, Th1 and Th2 cell differentiation, Human T-cell leukemia virus 1 infection, Allograft rejection, Epstein-Barr virus infection, Type I diabetes mellitus, IL-17, and Phagosome signaling pathways. We used the GOBubble and GOCluster functions of the GOplot package to plot the pathway enrichment images, and they are shown in Fig. 4 (d) and Fig. 5.

\section{Gene-set enrichment analysis in RA}

Digging deeper into the RA group's signaling pathways by gene-set enrichment analysis(GSEA) (Fig. 6), we found the following additional signaling pathways: Intestinal immune network for IgA production, Natural killer cell-mediated cytotoxicity, Primary immunodeficiency, Rheumatoid arthritis, Th1, and Th2 cell differentiation, Th17 cell differentiation, B cell receptor, p53, TNF, Toll - like receptor, AMPK, T cell, ErbB, FoxO, Insulin, PI3K Akt, TGF - beta, Chemokine, MAPK, NF - kappa B, Phospholipase D, cGMP - PKG, PPAR, and AGE - RAGE signaling pathways.

\section{Construction protein-protein interaction networks}

We logged into the STRING database website, entered these differentially expressed genes, and obtained the "string_interactions.tsv" file. For the "string_interactions.tsv" file, we used version 3.8.0 of Cytoscape software to construct the PPI network. This network demonstrates these DEGs' relationships and functions, and we set out to remove isolated nodes to derive the protein interaction network of RA, which contains 264 nodes and 999 links. We visualized the top 30 genes and displayed a bar chart of these 30 genes using $\mathrm{R}$ software. This situation implies that these $30 \mathrm{DEG}$ s have more interconnections and interactions with other genes and have an important central role in biological processes. (Fig. 7b).

\section{Identification of HUB genes and inflammation, immune-related HUB genes}

The top ten hub genes were derived by selecting the MCC algorithm. these top ten hub genes include Ccr1,Ccr2,Ccr5,Ccr7,Cxcl5,Cxcl6,Cxcl13,Cc/13, Adcy2 and Pnoc. shown in Fig. 7 (a).

We selected biofunctional terms related to inflammation and immunity for gene prediction and took intersections of these genes with hub genes. We derived the inflammation and immunity-related hub genes as 
follows: Ccr2, Ccr7, Cxcl5. Cxcl6, Cc/13, and Cxc/13. as shown in Fig. 10

\section{Analysis of immune infiltration in RA}

We derived immune infiltration differences by the CIBERSORT algorithm from 22 immune cell subpopulations between RA and normal synovial tissue. Figure 8 (a) The descending PCA method allowed to find significantly biased clustering and individual differences in the proportion of immune cells in the RA group versus normal controls. Figure 8 (d) The result of the heat map correlation showed that neutrophils and resting NK cells correlated positively (value $=0.71$ ). There was also a positive correlation between CD4 naive $T$ cells and resting NK cells (value $=0.59$ ), and CD8 T cells had a significant negative correlation with CD4 memory resting $T$ cells (value $=-0.49)$. There was also a significant negative correlation between plasma cells and activated NK cells (value $=-0.49$ ). Figure 8 (b) By screening, the immune cell gene expression matrix of 71 samples were obtained, and the heatmap was plotted to visualize the difference in expression in the normal and RA groups of 22 immune cells. As shown in Fig. 8 (c) Finally, violin plots were drawn and analyzed for immune cells' content in the 27 normal and 44 RA groups. It was concluded that RA tissues contained higher proportions of Plasma cells, follicular helper T cells, Monocytes, CD8 T cells, M0 macrophages, and gamma delta T cells. In contrast, regulatory T cells (Tregs), activated NK cells, CD 4 memory resting T cells, M1 Macrophages, resting Dendritic cells, Eosinophils, activated Mast cells, and resting Mast cells, were relatively low(Fig. 9).

\section{Discussion}

The pathogenesis of RA is centered on inflammation and immune response. One of RA's main clinical features is chronic synovitis, which progresses to cartilage and bone damage. Therefore, targeted analysis of these key genes, pathway molecules and immune infiltrations that are altered in disease will facilitate the discovery of valid and reliable biomarkers for early diagnosis, targeted personalized therapy and delayed disease progression, as well as facilitate the shift from a single-parameter model to a multi-parameter systemic model of traditional medical concepts[48, 49]. In this study, four knee synovial gene microarray expression data were downloaded from the GEO database. We mined these data to derive differentially expressed genes between RA synovial tissue and healthy controls. We found that 275 genes were significantly up-regulated, and 163 genes were significantly down-regulated among these differentially expressed genes. We expect that the hub genes, molecular pathways, and immune infiltration of inflammatory immune cells derived from the bioinformatics analysis of these differentially expressed genes will provide novel ideas and concepts for RA's diagnosis and treatment. The results of this study are summarized below.

\section{Analysis of molecular pathways that play a diagnostic and therapeutic role in RA}

Through KEGG and GSEA analysis, The molecular pathways in the knee synovial membrane of RA have been primarily involved in the biological processes of chemotaxis, adhesion, proliferation, differentiation, activation, and regulation of inflammatory immune cells leukocytes, T cells, and monocytes. Such results also confirm that RA is a biological process with an intricate regulatory network involving various inflammatory immune cytokine interactions. Furthermore, signaling pathways such as NF-kB, FoxO, Toll-like receptors, PI3K, TGF-beta, MAPK, PPAR, AGE-RAGE, and cGMP-PKG are also involved. 
The NF-kB pathway is activated and up-regulated in the synovial tissue of patients with RA. Using specific antibodies that bind to IL-1 and IL-17, blocking the NF-KB signaling pathway reduces serum inflammatory cytokine levels and decreases the expression of IL-1, IL-2, IL-6, IL-17, TNF-a, interferon- $\gamma$, and matrix metalloproteinase-3. Increasing the expression of IL-10 inhibits bone destruction, reduces histological damage, decreases the severity of arthritis, and has a therapeutic effect on RA[50,51].

During RA, the FoxO signaling pathway is down-regulated. One experiment found that in RA patients' peripheral blood, the expression of Fox01 mRNA was significantly reduced. Fox01 overexpression has induced apoptosis of RA synovial cells. Expression levels have been negatively correlated with the disease's activity, which is consistent with our results[52].

A suitable blockade of Toll-like receptor (TLR) activation has been reported to have an inhibitory effect on RA development during disease progression $[53,54]$. The TLR4 inhibitor TAK-242, which inhibits IL-6, MMP-1, and VEGF expression, reduces serum IL-6 and VEGF and has an inhibitory effect on the NF-KB pathway. The inflammatory status of joint tissues has significantly improved, thus controlling RA progression[55].

It has been shown that transforming growth factor (TGF) in synovial tissue maintains the knee joint's normal physiological function, that increased expression of TGF in RA synovium may lead to abnormal synovial growth. That inhibition of the TGF signaling pathway reduces the survival and migration of synovial fibroblasts and attenuates pulmonary fibrosis in RA rats[56]. Betulinic acid (BA) inhibited the migration and invasion of RA synovial cells, suppressed vascular endothelial growth factor transcription and TGF. It also inhibited NF-3B inflammatory pathway-related protein expression, decreased IL-1 and IL-6 inflammatory mediator levels, and reduced RA symptoms in rats[57].

The PI3K/AKT signaling pathway is activated and up-regulated in RA. Shikonin(SKN) down-regulates PI3K and Akt's expression, inhibiting the phosphorylation and gene-level signaling molecules such as ERK1/2, JNK1/2, and p38, and exerts anti-RA angiogenic effects[58]. Cinnamaldehyde (CA) can block PI3K/AKT signaling pathway and inhibit the proliferation and infiltration of rheumatoid synovial cells, which has potential therapeutic effects on RA[59]. Berberine inhibits inflammatory proliferation of synovial cells, suppresses DC activation, regulates Th17/Treg balance, and prevents cartilage and bone destruction by regulating various signaling pathways involved in inflammatory responses, including PI3K/Akt. Such molecular targets may explore new RA treatment targets[60].

In RA synovial tissue, MAPK signaling pathway activation expression is increased. Its activation plays a regulatory role in differentiating monocytes and cell survival. In mice, members of the receptor families PAQR11, progesterone, and AdipoQ regulate in vitro monocyte and macrophage differentiation. In vivo Paqr11 knockdown deletion inhibits monocyte differentiation, encourages cell survival, and delays RA progression[61]. Silencing of IncRNA para nuclear assembly transcript 1 promotes miR-129 and miR-204, inhibits the MAPK signaling pathway. Lipoxin A4 (LXA4), a MAPK signaling pathway p38 inhibitor, decreased p38 expression in mouse synovial tissues, reduced proliferation of synovial tissue and inflammatory cell infiltration, reduced proliferation of RA severity, and produced a protective effect in arthritic mice[62].

In various diseases, peroxisome proliferator-activated receptors (PPAR) are involved in normal physiological and pathological processes. Expression of PPAR is significantly lower than normal in RA synovial tissues. 
Down-regulation of PPAR promotes the expression of Cyclin D1, MMP1, and MMP9, and PPAR up-regulation may induce Wnt/ $\beta$-catenin signaling activation, which plays a vital role in the synovial cells of RA. One study found that pioglitazone, a receptor agonist activated by peroxisome proliferators, promotes vasoprotective and anti-inflammatory effects in RA, significantly improves aortic elasticity, and decreases inflammation and activity of the disease[63, 64].

MiR-34a can activate the p53 signaling pathway and inhibit the abnormal growth of synovial tissue and inflammatory process in RA. Other studies have also found that mutations in the P53 signaling pathway, a traditional oncogene, may be associated with anti-rheumatic RA resistance[65].

AGE-RAGE signaling pathway and CGMP-PKG have not been reported in rheumatoid arthritis. Still, By activating NOx-1 and reducing SOD-1 expression, AGE/RAGE signaling has been shown to increase oxidative stress, thus promoting vascular calcification mediated by diabetes. And oxidative stress plays a key role in the synovial lesion process in RA, which needs to be further verified [66].

Natriuretic Peptides have been shown to cause inflammatory dissociation by activating the cGMP/PKG signaling pathway. By increasing intracellular CGMP levels, phosphodiesterases are activated while interfering with caspase-8 cleavage. It inhibits the activation pathway of inflammatory vesicles, thus acting as an antiinflammatory and immunomodulatory agent. Therefore, we suggest that the signaling pathway of cGMP-PKG plays a significant role in RA and needs further research [67].

\section{Analysis of Hub genes that play a diagnostic and therapeutic role in $R A$}

We used STRING online database tool and R language to derive the top30 protein interaction networks, and Cytoscape software's Cytohubba plug-in was also used, and ten genes were filtered out such as Ccr1, Ccr2, $C c r 5, C c r 7, C x c / 5, C x c l 6, C x c / 13, C c / 13, A d c y 2$, and Pnoc. We then used the R language GOplot package to derive six hub genes associated with inflammatory immunity: Ccr2, Ccr7, Cxc/5. Cxcl6, Cc/13and Cxc/13,

Our study revealed that these hub genes are mainly chemokine and receptor-related genes. Chemokines are produced by synovial macrophages and exert chemotactic effects on inflammatory immune cells such as neutrophils, lymphocytes, and monocytes and are closely associated with vasculitis development. CCR, CXCL, and $\mathrm{CCL}$, as essential components and receptors of the chemokine family, are closely related to RA development.

The CC Chemokine Receptor (CCR) is an integral membrane protein. The targeting of chemokines or chemokine receptors is a promising therapeutic strategy for the treatment of chronic inflammation. Small CCR1 and CCR2 molecule antagonists are effective at blocking inflammatory immune cell migration. Reduces the inflammatory response and decreases pain caused by chronic inflammation [68].

The knockdown of CCR5 and the application of PD98059 (mitogen-activated protein kinase 1 inhibitor) in rats resulted in a significant decrease in interleukin-6, metalloproteinase-1, metalloproteinase-3, and tumor necrosis factor levels. In addition to substantial reductions in JNK1, ERK1, p38, Cyclin protein, and Bcl-2, CCR5 may inhibit synovial cell activity, promote synovial cell apoptosis, and suppress the inflammatory response of synovial cells in RA rats via the MAPK pathway. For RA, it may provide a new therapeutic target[69]. 
The CCR7 chemokine receptor plays a key role in health and disease by directing immune cells' migration, particularly DCs and T cells. Due to impaired CCR7 signaling, immune responses and misdirection of immune cells can lead to autoimmune diseases. [70, 71].

Inflammatory migration and erosive phenotypes have been observed in patients with RA. Identifying new pathways involved in various stages of the pathology of RA will provide valuable insights into different inflammatory immune cells' mechanical behavior and strategies to suppress their activity. CCR7 is a marker of RA synovial fluid macrophages, and in early RA, monocytes infiltrate synovial tissue. By blocking CCR7/ CCL21 in synovial fluid, monocyte migration is prevented. It increases the number of M1 macrophages and raises the levels of IL- 6 and IL-23. Increased transcription of M1 macrophage cytokines leads to the differentiation of primary T cells into Th17 cells, and M1 macrophage-driven Th17 polarization promotes osteoclast formation in RA during the aggressive phase of the disease. They are extending joint inflammation to bone erosion. It also induces neovascularization, further aggravating disease progression. CCR7/CCL21 is an exciting emerging RA therapy target, and obstructing its function reduces or eliminates RA immune-inflammatory infiltration. They play a major role in delaying or blocking the RA pathological process[72, 73].

For how CCR7 signaling directs cell migration and infiltration, we need to develop new tools to assess and monitor CCR7 signaling. The latest study identifies human CCR7 by novel nanotechnology. It interacts with CCR7 through bimolecular fluorescence

complementary recognition without interfering with $\mathrm{G}$ protein coupling and downstream signaling. Targeted analysis of the migration and invasion process of CCR7 [74].

Chemokine C-X-C motif chemokine ligand 5 (CXCL5) has functions such as chemotaxis of neutrophils, proangiogenesis, and involvement in inflammatory responses. Its pathological angiogenesis is highly correlated with RA activity[75].

CXCL13 is a known B cell chemokine that promotes B lymphocyte migration by interacting with its receptor CXCR5. CXCL13 and CCL20 act synergistically to increase B cell migration, leading to autoimmune inflammation, closely associated with disease activity $[76,77]$.

By recruiting monocytes and lymphocytes, CC motif chemokines are thought to be involved in RA's pathogenesis. In both serum and synovial tissue, the expression of CCL13 is elevated in RA patients. Interestingly, tumor necrosis factor-alpha positively regulates CCL13 expression and inhibits synovial fibroblast apoptosis[78]. RA prevalence in women is higher than in men, and 17-estradiol mediates cellular activation signals in synovial fibroblasts via ERK-1/2, leading to uncontrolled apoptosis, increased matrix metalloproteinase-3 production, and excessive CCL13 production, leading to the progression of RA [79].

However, Adcy2 and Pnoc genes have not been reported in RA studies. Adenylate cyclase 2 (Adcy2), a member of adenylate cyclase class $B$, plays a crucial role in promoting phosphorylation, glycogen synthesis, and catabolism. By studying the anti-migratory effect of adenylate cyclase-related protein 1 in pancreatic cancer cells, cyclic adenosine monophosphate was found to be a second messenger regulating the migration and invasion of pancreatic cancer cells. Its elevation prevented the migration and invasion of pancreatic ductal carcinoma cells [80]. We speculate that $A d c y 2$ may play a role in inflammatory immune cell migration and infiltration in RA and merits further investigation.

Page $10 / 33$ 
The prepronociceptin (Pnoc) gene encodes bioactive peptides involved in sensory, emotional, cognitive, and neurogenesis. The interaction between these active peptides and the corresponding receptors can modulate inflammation and immune diseases. Silencing the gene reduces inflammatory factor levels, oxidative stress, and glial fibrillary acidic protein expression. Conversely, overexpression of this gene reverses the changes in the above biochemical indicators[81]. Considering that it can regulate inflammation and immunity, we hypothesized that this gene might play an important role in RA's inflammatory response and potential therapeutic target.

\section{Analysis of immune infiltrating cells that play a diagnostic and therapeutic role in RA}

To further investigate the RA synovium role of inflammatory immune cell infiltration, we performed immune infiltration analysis on a combined dataset of four databases by the CIBERSORT algorithm. We found that CD8 T cells, Plasma cells, Monocytes, follicular helper T cells, gamma delta T cells, and M0 macrophages were significantly elevated in RA. In contrast, CD4 memory resting T cells, regulatory T cells (Tregs), M1 Macrophages,

activated NK cells, resting Dendritic cells, resting Mast cells, Eosinophils, and activated Mast cells were significantly reduced in the RA synovial tissue.

Plasma cells (PC) are also known as antibody-secreting cells. With antigen-presenting cells and Th cells, mature $B$ cells become activated $B$ cells after receiving antigen stimulation. They then differentiate into plasma cells, which synthesize different kinds of immunoglobulins and secrete them. $\beta$-ARR2 has been found to be a crucial protein mediating the desensitization and internalization of inflammatory and immune responses involving $G$ protein-coupled receptors. Its deletion inhibits the endocytosis of Toll-like receptor 4 (TLR4) on B lymphocyte membranes while activating the NF-KB signaling pathway, increasing plasma cell differentiation and antibody production and exacerbating arthritis symptoms[82]. Myeloid suppressor cells derived from granulocytes secrete exosomes, transport different bioactive molecules, and play a regulatory role in immune cells. It also promotes the secretion of IL-10 from splenic B cells, reduces the proportion of plasma and follicular helper T cells and serum IgG levels, and mitigates rheumatoid arthritis symptoms in mice[83]. It is evident that plasma cells play an essential role in RA and deserve further study.

In RA, CD8 + CD28-T cells are significantly elevated and may be associated with T-lymphocyte homeostasis dysregulation. There is also an increase in their supracellular expression of programmed death receptor-1 (PD1). When regulating T lymphocytes, PD-1 plays a key role. Although PD-1 induces immunosuppression of effector T cells in synovial inflammation, its expression is up-regulated in synovial inflammation, closely correlating with the severity of its disease [84]. Another study found that CD8 $+T$ cells are involved in the pathogenesis of RA through the release of pro-inflammatory and cytolytic mediators and that targeting lactate dehydrogenase remodels CD8 $+T$ cells and changes the metabolism of glucose and glutamine, thereby reducing the adipogenic, migratory and proliferative capacity of $C D 8+T$ cells while losing the ability to induce a pro-inflammatory phenotype in B cells [85].

One of the potential mechanisms promoting RA is the imbalance in the ratio of M1 macrophages, which produce pro-inflammatory factors, to M2 macrophages, which produce anti-inflammatory factors.M2 
macrophages may have a positive role in delaying the development of RA. In contrast, M0 macrophages may have a potential role in the immune imbalance associated with RA pathogenesis. Our results found a significant increase in the proportion of $\mathrm{M} 0$ macrophages and a substantial decrease in the proportion of M1 macrophages in RA's synovial tissue. The common knowledge contradicts this that M1 macrophages should be significantly up-regulated in the synovium of RA. It has been found that M0 macrophages can differentiate into M1 and M2 macrophages under certain circumstances, and these paradoxical phenomena and whether M0 macrophages are converted to M1 macrophages in the inflammatory setting in RA deserve further investigation [86].

Monocytes are attracted to pro-inflammatory mediators in response to inflammation or tissue injury, differentiate toward macrophages, activate macrophages, and the Paqr11 gene regulates monocyte-tomacrophage differentiation. Knockdown of Paqr11 in mice inhibited monocytes' differentiation and delayed RA progression [61]. Tumor necrosis factor-alpha and IL-6 were used in other experiments to induce osteoclasts with the ability to resorb bone matrix to stimulate peripheral blood monocytes. The expression of IL-1 $1 \beta$, IL-12, TNF alpha, and MMP3 has been significantly increased in tumor necrosis, factor-alpha, and IL-6-induced osteoclasts. RA and other joint destruction-related inflammatory arthritis may involve these monocytes with the capacity to resorb bone matrix[87].

Dendritic cells (DCs) are the nexus of innate and acquired immunity, and increased expression of proinflammatory cytokines, chemokines, and adhesion molecules was found in DCs by culturing RA synovial tissue in vitro. Hydroxychloroquine (HCQ) is one of the most commonly used immunosuppressive agents in treating RA. HCQ inhibits DC maturation and migration to lymph nodes, decreases CXCR4 expression and interferon-a secretion, and DC activation is involved in RA's pathogenesis. HCQ protects against RA by blocking TLR9[88]. TARM1 is a member of the leukocyte immunoglobulin-like receptor family. Its expression is elevated in the joints of a mouse model of RA. It is an important stimulus for dendritic cell maturation, which may be a good target for the treatment of autoimmune diseases[89].

Mast cells are tissue-resident innate immune cells involved in the pathogenesis of many autoimmune diseases; they are mainly present in RA's synovial tissue. Their activation is associated with the amelioration of inflammation. However, a growing body of proof indicates that mast cells can act as modifiable immune cells with pro-and anti-inflammatory functions. Synovial mast cells are a potential research hotspot for this subtle, conflicting, and exciting hypothesis[90].

Substance $\mathrm{P}(\mathrm{SP})$ is a pro-inflammatory substance, and activated synovial mast cells rapidly degrade SP in RA while downregulating SP-mediated synovial cell activation. On the other hand, SP activates inflammatory mediators induced by synoviocytes, suggesting a dual regulation of SP-mediated synovial mast cell inflammation in RA[91]. It has been found that gene expression of synovial mast cells is negatively correlated with disease activity. When IL-33 activates synovial mast cells, they produce an immunomodulatory phenotype and inhibit monocyte activation[92]. However, a study found that mast cells are important targets of Toll-like receptor ligands and immune complexes. Mast cells greatly enhance the inflammatory response of synovial tissue in RA through these pathways' combined activation[93].

Eosinophils have a pro-inflammatory role in asthma. However, recent studies have shown that eosinophils have a pro-soluble effect in RA. After induction of eosinophil asthma, arthritis subsided, and joint tissue was 
protected in mice. Single-cell RNA sequencing approaches identified a specific subpopulation of regulatory eosinophils in the joints, distinct from inflammatory eosinophils in the lungs. The reduction of eosinophils instead eliminated the beneficial effects of asthma on arthritis. Such a result is consistent with our study that concluded a significant down-regulation of eosinophils in RA[94].

The anti-inflammatory effect of eosinophils was also confirmed in another experiment. Eosinophil treatment reduced iNOS, TNF-a, IL-6, and IL-12 levels, while Arg1, transforming growth factor- $\beta$, IL-10, and IL-13, increased while inhibiting MAPK signaling polarizing M2 macrophages, exerting anti-inflammatory and reducing RA symptoms[95]. The double-edged role of these eosinophils needs to be studied in depth.

\section{Conclusion And Expert Recommendations}

In conclusion, we conducted a detailed bioinformatics study of RA gene expression profiles. Genes with significant differential expression were screened. Functional and signaling pathway enrichment analysis was performed on these genes. We found that Toll-like receptors, AMPK, MAPK, TNF, ErbB, P53, FoxO, TGF- beta, $\mathrm{PI} 3 \mathrm{~K}$, and NF-KB pathways also play critical roles in RA in addition to signaling pathways closely related to inflammatory immune responses. Next, We imputed ten hub genes and six inflammatory immune-related hub genes from PPI, among which Adcy2 and Pnoc. were not reported in RA studies, suggesting that they may be worthy targets for further research. Finally, We deduced the infiltration of different inflammatory immune cells in RA's synovial tissue by the CIBERSORT algorithm. In short, these results may contribute to the understanding of the biological processes associated with RA and the development of targeted therapeutic approaches.

We recommend this research article.RA is a chronic, complex disease with multi-gene, multi-pathway, and multicellular involvement, involving alterations in multi-level molecular networks of genomic, transcriptomic, proteomic, and various inflammatory immune cells. In clinical practice, patient samples can be collected for high-throughput sequencing. Through bioinformatics analysis, key genes and pathway molecules in the network can be obtained. The regulation and interactions between various genes and pathway molecules and cellular networks can be analyzed, integrated, and mined by computer science such as big data, machine learning, neural networks, artificial intelligence, biomaterials, and cell simulation. Targeted and rational prediction and analysis lead to effective personalized diagnosis and treatment. We also promote the transformation of traditional empirical and reactive medical services to predictive, targeted, and personalized medical services and improve RA patients' services by combining medicine with other disciplines such as mathematics, statistics, computers, and emerging materials under the innovative concept of the three elements of PPPM.

\section{Abbreviations}

RA: Rheumatoid arthritis,

KEGG: Kyoto Encyclopedia of Genes and Genomes pathway,

GO: Gene Ontology's enrichment analysis,

GSEA: Gene-set enrichment analysis, 
PPPM: Predictive preventive personalized medicine,

DEGs: Differentially expressed genes,

PPI: protein-protein interaction networks,

SKN: Shikonin,

LXA4: Lipoxin A4,

PPAR: peroxisome proliferator-activated receptors,

CCR: The CC Chemokine Receptor,

CXCL: Chemokine C-X-C motif chemokine ligand,

Adcy2: Adenylate cyclase 2,

Pnoc: prepronociceptin,

TLR4: Toll-like receptor 4,

PC: Plasma cells,

PD-1: programmed death receptor-1,

DCs: Dendritic cells,

HCQ: Hydroxychloroquine,

SP: Substance P,

BP: Biological Process

CC: Cellular Component,

MF: Molecular Function,

\section{Declarations}

\section{Funding}

Not applicable.

\section{Conflicts of interest/Competing interests}

The authors declare that they have no conflict of interest with the Gene Expression Omnibus (GEO) database used in this study. 
All data is real and guarantee the validity of results.

\section{Authors' contributions}

Sheng Fang conceived the original idea and designed the outlines of the study. Xiao Fang, Xin Xu, Lin Zhong, and An-quan Wang Helped collect, organize, and check the data. Wei-lu Gao and Zong-Sheng Yin aided in revising the manuscript. All authors have read and approved the final manuscript.

\section{Ethics approval}

Not applicable.

\section{Consent to participate}

Not applicable.

\section{Consent for publication}

Not applicable.

\section{Acknowledgements}

Not applicable.

\section{References}

1. Smolen JS. Insights into the treatment of rheumatoid arthritis: A paradigm in medicine. J Autoimmun [Internet]. Elsevier; 2020;110:102425. Available from: https://doi.org/10.1016/j.jaut.2020.102425.

2. Mclnnes IB, Schett G. Pathogenetic insights from the treatment of rheumatoid arthritis. Lancet [Internet]. Elsevier Ltd; 2017;389:2328-37. Available from: http://dx.doi.org/10.1016/S0140-6736(17)31472-1.

3. Weyand CM, Goronzy JJ. The immunology of rheumatoid arthritis. Nat Immunol. 2021;22:10-8.

4. Boissier MC, Semerano L, Challal S, Saidenberg-Kermanac'h N, Falgarone G. Rheumatoid arthritis: From autoimmunity to synovitis and joint destruction. J Autoimmun. 2012;39:222-8.

5. Arend WP, Firestein GS. Pre-rheumatoid arthritis: Predisposition and transition to clinical synovitis. Nat Rev Rheumatol [Internet]. Nature Publishing Group; 2012;8:573-86. Available from: http://dx.doi.org/10.1038/nrrheum.2012.134.

6. Boissier MC. Cell and cytokine imbalances in rheumatoid synovitis. Jt Bone Spine [Internet]. Elsevier Masson SAS; 2011;78:230-4. Available from: http://dx.doi.org/10.1016/j.jbspin.2010.08.017.

7. Coutant F, Miossec P. Evolving concepts of the pathogenesis of rheumatoid arthritis with focus on the early and late stages. Curr Opin Rheumatol. 2020;32:57-63.

8. Golubnitschaja O, Baban B, Boniolo G, Wang W, Bubnov R, Kapalla M, et al. Medicine in the early twentyfirst century: Paradigm and anticipation - EPMA position paper 2016. EPMA J [Internet]. EPMA Journal; 2016;7:1-13. Available from: http://dx.doi.org/10.1186/s13167-016-0072-4. 
9. Schultzhaus Z, Wang Z, Stenger D. CRISPR-based enrichment strategies for targeted sequencing [Internet]. Biotechnol. Adv. Elsevier Inc; 2021. Available from: https://doi.org/10.1016/j.biotechadv.2020.107672.

10. Ballester LY, Luthra R, Kanagal-Shamanna R, Singh RR. Advances in clinical next-generation sequencing: Target enrichment and sequencing technologies. Expert Rev Mol Diagn. 2016;16:357-72.

11. Su Z, Ning B, Fang H, Hong H, Perkins R, Tong W, et al. Next-generation sequencing and its applications in molecular diagnostics. Expert Rev Mol Diagn. 2011;11:333-43.

12. Thakur R, Laye JP, Lauss M, Diaz JMS, O’Shea SJ, Pozniak J, et al. Transcriptomic analysis reveals prognostic molecular signatures of stage I melanoma. Clin Cancer Res. 2019;25:7424-35.

13. Jarvis JN. Diagnostic and prognostic potential of gene microarrays in rheumatoid arthritis. Expert Rev Mol Diagn. 2005;5:655-9.

14. Häupl T, Stuhlmüller B, Grützkau A, Radbruch A, Burmester GR. Does gene expression analysis inform us in rheumatoid arthritis? Ann Rheum Dis. 2010;69.

15. Hu J, Yu A, Othmane B, Qiu D, Li H, Li C, et al. Siglec15 shapes a non-inflamed tumor microenvironment and predicts the molecular subtype in bladder cancer. Theranostics. 2021;11:3089-108.

16. Ren C, Li M, Du W, Lü J, Zheng Y, Xu H, et al. Comprehensive Bioinformatics Analysis Reveals Hub Genes and Inflammation State of Rheumatoid Arthritis. Biomed Res Int. 2020;2020.

17. Ma C, Lv Q, Teng S, Yu Y, Niu K, Yi C. Identifying key genes in rheumatoid arthritis by weighted gene coexpression network analysis. Int J Rheum Dis. 2017;20:971-9.

18. Xiong Y, Bo-Bin M, Liu MF, Xue H, Wu QP, Liu GH. Bioinformatics analysis and identification of genes and molecular pathways involved in synovial inflammation in rheumatoid arthritis. Med Sci Monit. 2019;25:2246-56.

19. Zuo B, Zhu JF, Xiao F, Wang CL, Shen Y, Chen XD. Identification of novel biomarkers and candidate small molecule drugs in rheumatoid arthritis and osteoarthritis based on bioinformatics analysis of highthroughput data. Biosci Rep. 2020;40:1-13.

20. Ungethuem $U$, Haeupl T, Witt H, Koczan D, Krenn V, Huber H, et al. Molecular signatures and new candidates to target the pathogenesis of rheumatoid arthritis. Physiol Genomics. 2010;42 A:267-82.

21. Woetzel D, Huber R, Kupfer P, Pohlers D, Pfaff M, Driesch D, et al. Identification of rheumatoid arthritis and osteoarthritis patients by transcriptome-based rule set generation. Arthritis Res Ther. 2014;16.

22. Brouwer S, Bradlow AR. PDF hosted at the Radboud Repository of the Radboud University Nijmegen Article information: 2015;3-6.

23. Leek JT, Johnson WE, Parker HS, Jaffe AE, Storey JD. The SVA package for removing batch effects and other unwanted variation in high-throughput experiments. Bioinformatics. 2012;28:882-3.

24. Zhang S, Wu Z, Xie J, Yang Y, Wang L, Qiu H. DNA methylation exploration for ARDS: A multi-omics and multi-microarray interrelated analysis. J Transl Med [Internet]. BioMed Central; 2019;17:1-11. Available from: https://doi.org/10.1186/s12967-019-2090-1.

25. Han W, Li L. Evaluating and minimizing batch effects in metabolomics. Mass Spectrom Rev. 2020;1-22.

26. Zhang Y, Evan Johnson W, Parmigiani G. Robustifying genomic classifiers to batch effects via ensemble learning. bioRxiv. 2019;1-8. 
27. Ritchie ME, Phipson B, Wu D, Hu Y, Law CW, Shi W, et al. Limma powers differential expression analyses for RNA-sequencing and microarray studies. Nucleic Acids Res. 2015;43:e47.

28. Holland CH, Tanevski J, Perales-Patón J, Gleixner J, Kumar MP, Mereu E, et al. Robustness and applicability of transcription factor and pathway analysis tools on single-cell RNA-seq data. Genome Biol Genome Biology. 2020;21:1-19.

29. Koopmans F, van Nierop P, Andres-Alonso M, Byrnes A, Cijsouw T, Coba MP, et al. SynGO: An EvidenceBased, Expert-Curated Knowledge Base for the Synapse. Neuron. 2019;103:217-34.e4.

30. Goto MK. and S. KEGG Kyoto Encyclopedia of Genes and Genomes. Nucleic Acids Res. 2000;28:27-30.

31. Niu SP, Zhang YJ, Han N, Yin XF, Zhang DY, Kou YH. Identification of four differentially expressed genes associated with acute and chronic spinal cord injury based on bioinformatics data. Neural Regen Res. 2021;16:865-70.

32. Mathur R, Rotroff D, Ma J, Shojaie A, Motsinger-Reif A. gsea Gene set analysis methods: A systematic comparison. BioData Min BioData Mining. 2018;11:1-19.

33. Xu Y, He Q, Lu Y, Tao F, Zhao L, Ou R. MicroRNA-218-5p inhibits cell growth and metastasis in cervical cancer via LYN/NF-KB signaling pathway. Cancer Cell Int [Internet]. BioMed Central; 2018;18:1-15. Available from: https://doi.org/10.1186/s12935-018-0673-1.

34. Audette DS, Anand D, So T, Rubenstein TB, Lachke SA, Lovicu FJ, et al. Prox1 and fibroblast growth factor receptors form a novel regulatory loop controlling lens fiber differentiation and gene expression. Dev. 2016;143:318-28.

35. Ning Y, Le, Yang ZQ, Xian SX, Lin JZ, Lin XF, Chen WT. Bioinformatics analysis identifies hub genes and molecular pathways involved in sepsis-induced myopathy. Med Sci Monit. 2020;26:1-10.

36. Szklarczyk D, Gable AL, Nastou KC, Lyon D, Kirsch R, Pyysalo S, et al. The STRING database in 2021: customizable protein-protein networks, and functional characterization of user-uploaded gene/measurement sets. Nucleic Acids Res. Oxford University Press; 2021;49:D605-12.

37. Szklarczyk D, Gable AL, Lyon D, Junge A, Wyder S, Huerta-Cepas J, et al. STRING v11: Protein-protein association networks with increased coverage, supporting functional discovery in genome-wide experimental datasets. Nucleic Acids Res. 2019;47:D607-13.

38. Otasek D, Morris JH, Bouças J, Pico AR, Demchak B. Cytoscape Automation: Empowering workflow-based network analysis. Genome Biol Genome Biology. 2019;20:1-15.

39. Shannon P, Markiel A, Ozier O, Baliga NS, Wang JT, Ramage D, et al. Cytoscape: A software Environment for integrated models of biomolecular interaction networks. Genome Res. 2003;13:2498-504.

40. Sun G, Li Y, Peng Y, Lu D, Zhang F, Cui X, et al. Identification of differentially expressed genes and biological characteristics of colorectal cancer by integrated bioinformatics analysis. J Cell Physiol. 2019;234:1521524.

41. Shigemizu D, Akiyama S, Higaki S, Sugimoto T, Sakurai T, Boroevich KA, et al. Prognosis prediction model for conversion from mild cognitive impairment to Alzheimer's disease created by integrative analysis of multi-omics data. Alzheimer's Res Ther. Alzheimer's Research \& Therapy; 2020;12:1-12.

42. Liu S, Xie X, Lei H, Zou B, Xie L. GOplot Identification of key circrnas/IncRNAs/miRNAs/mRNAs and pathways in preeclampsia using bioinformatics analysis. Med Sci Monit. 2019;25:1679-93. 
43. Jopek K, Tyczewska M, Celichowski P, Malendowicz LK, Rucinski M. goplot Transcriptome profile in unilateral adrenalectomy-induced compensatory adrenal growth in the rat. Int J Mol Sci. 2018;19.

44. Walter W, Sánchez-Cabo F, Ricote M. GOplot. An R package for visually combining expression data with functional analysis. Bioinformatics. 2015;31:2912-4.

45. Jiménez-Sánchez A, Cast 0 , Miller M. Comprehensive benchmarking and integration of tumour microenvironment cell estimation methods. bioRxiv. 2018;1-21.

46. Yang Z, Wei X, Pan Y, Xu J, Si Y, Min Z, et al. A new risk factor indicator for papillary thyroid cancer based on immune infiltration. Cell Death Dis. 2021;12.

47. Newman AM, Liu CL, Green MR, Gentles AJ, Feng W, Xu Y, et al. Robust enumeration of cell subsets from tissue expression profiles. Nat Methods. 2015;12:453-7.

48. Bubnov RV, Spivak MY, Lazarenko LM, Bomba A, Boyko NV. Probiotics and immunity: Provisional role for personalized diets and disease prevention. EPMA J [Internet]. EPMA Journal; 2015;6:1-11. Available from: http://dx.doi.org/10.1186/s13167-015-0036-0.

49. Cheng T, Zhan X. Pattern recognition for predictive, preventive, and personalized medicine in cancer. EPMA J EPMA Journal. 2017;8:51-60.

50. Wu Q, Wang Y, Wang Q, Yu D, Wang Y, Song L, et al. The bispecific antibody aimed at the vicious circle of IL-1 $\beta$ and IL-17A, is beneficial for the collagen-induced rheumatoid arthritis of mice through NF-KB signaling pathway. Immunol Lett [Internet]. Elsevier BV; 2016;179:68-79. Available from: http://dx.doi.org/10.1016/j.imlet.2016.09.001.

51. Kong X, Liu C, Zhang C, Zhao J, Wang J, Wan H, et al. The suppressive effects of Saposhnikovia divaricata (Fangfeng) chromone extract on rheumatoid arthritis via inhibition of nuclear factor-kB and mitogen activated proteinkinases activation on collagen-induced arthritis model. J Ethnopharmacol [Internet]. Elsevier; 2013;148:842-50. Available from: http://dx.doi.org/10.1016/j.jep.2013.05.023.

52. Citation LO. UvA-DARE (Digital Academic Repository) Molecular mechanisms of histone deacetylases in rheumatoid arthritis fibroblast-like synoviocytes Angiolilli, C. 2020.

53. Review Toll-like receptor pathways in autoimmune diseases Ji-Qing Chen MD, 2. Peter Szodoray MD., PhD, 1 Margit Zeher MD, PhD, DSc Division of Clinical Immunology, Institute of Medicine, University of Debrecen, Centre for Immune Regulation, Departm. :1-50.

54. Kim KW, Kim BM, Won JY, Lee KA, Kim HR, Lee SH. Toll-like receptor 7 regulates osteoclastogenesis in rheumatoid arthritis. J Biochem. 2019;166:259-70.

55. Samarpita S, Kim JY, Rasool MK, Kim KS. Investigation of toll-like receptor (TLR) 4 inhibitor TAK-242 as a new potential anti-rheumatoid arthritis drug. Arthritis Res Ther Arthritis Research Therapy. 2020;22:1-10.

56. Wang S, Wang S, Li H, Zhu L, Wang Y. Inhibition of the TGF- $\beta$ /Smads signaling pathway attenuates pulmonary fibrosis and induces anti-proliferative effect on synovial fibroblasts in rheumatoid arthritis. Int $\mathrm{J}$ Clin Exp Pathol [Internet]. 2019;12:1835-45. Available from: http://www.ncbi.nlm.nih.gov/pubmed/31934007\%0Ahttp://www.pubmedcentral.nih.gov/articlerender.fcgi? artid=PMC6947118.

57. Kun-Liu, Wang JY, Zhang L, Pan YY, Chen XY, Yuan Y. Effects of betulinic acid on synovial inflammation in rats with collagen-induced arthritis. Int J Immunopathol Pharmacol. 2020;34. 
58. Liu C, He L, Wang J, Wang Q, Sun C, Li Y, et al. Anti-angiogenic effect of Shikonin in rheumatoid arthritis by downregulating PI3K/AKT and MAPKs signaling pathways [Internet]. J. Ethnopharmacol. Elsevier BV; 2020. Available from: https://doi.org/10.1016/j.jep.2020.113039.

59. Li X, Wang Y. Cinnamaldehyde Attenuates the Progression of Rheumatoid Arthritis through DownRegulation of PI3K/AKT Signaling Pathway. Inflammation Inflammation. 2020;43:1729-41.

60. Shen P, Jiao Y, Miao L, Chen J, hua, Momtazi-Borojeni AA. Immunomodulatory effects of berberine on the inflamed joint reveal new therapeutic targets for rheumatoid arthritis management. J Cell Mol Med. 2020;24:12234-45.

61. Lin Y, Huang M, Wang S, You X, Zhang L, Chen Y. PAQR11 modulates monocyte-to-macrophage differentiation and pathogenesis of rheumatoid arthritis. Immunology. 2021;0-2.

62. Chen J, Luo X, Liu M, Peng L, Zhao Z, He C, et al. Silencing long non-coding RNA NEAT1 attenuates rheumatoid arthritis via the MAPK/ERK signalling pathway by downregulating microRNA-129 and microRNA-204. RNA Biol [Internet]. Taylor \& Francis; 2021;0. Available from: https://doi.org/10.1080/15476286.2020.1857941.

63. Li XF, Sun YY, Bao J, Chen X, Li YH, Yang Y, et al. Functional role of PPAR-Y on the proliferation and migration of fibroblast-like synoviocytes in rheumatoid arthritis. Sci Rep [Internet]. Springer US; 2017;7:113. Available from: http://dx.doi.org/10.1038/s41598-017-12570-6.

64. Marder W, Khalatbari S, Myles JD, Hench R, Lustig S, Yalavarthi S, et al. The peroxisome proliferator activated receptor-y pioglitazone improves vascular function and decreases disease activity in patients with rheumatoid arthritis. J Am Heart Assoc. 2013;2:1-10.

65. Zhang KX, Ip CK, Chung SK, Lei KK, Zhang YQ, Liu L, et al. Drug-resistance in rheumatoid arthritis: the role of p53 gene mutations, $\mathrm{ABC}$ family transporters and personal factors. Curr Opin Pharmacol [Internet]. Elsevier Ltd; 2020;54:59-71. Available from: https://doi.org/10.1016/j.coph.2020.08.002.

66. Kay AM, Simpson CL, Stewart JA. The Role of AGE/RAGE Signaling in Diabetes-Mediated Vascular Calcification. J Diabetes Res. 2016;2016.

67. Mezzasoma L, Talesa VN, Romani R, Bellezza I. Anp and bnp exert anti-inflammatory action via npr$1 /$ cgmp axis by interfering with canonical, non-canonical, and alternative routes of inflammasome activation in human thp1 cells. Int J Mol Sci. 2021;22:1-17.

68. Moadab F, Khorramdelazad H, Abbasifard M. Role of CCL2/CCR2 axis in the immunopathogenesis of rheumatoid arthritis: Latest evidence and therapeutic approaches. Life Sci [Internet]. Elsevier Inc.; 2021;269:119034. Available from: https://doi.org/10.1016/j.Ifs.2021.119034.

69. Lan YY, Wang YQ, Liu Y. CCR5 silencing reduces inflammatory response, inhibits viability, and promotes apoptosis of synovial cells in rat models of rheumatoid arthritis through the MAPK signaling pathway. J Cell Physiol. 2019;234:18748-62.

70. Moschovakis GL, Förster R. Multifaceted activities of CCR7 regulate T-cell homeostasis in health and disease. Eur J Immunol. 2012;42:1949-55.

71. Van Raemdonck K, Umar S, Shahrara S. The pathogenic importance of CCL21 and CCR7 in rheumatoid arthritis. Cytokine Growth Factor Rev [Internet]. Elsevier; 2020;55:86-93. Available from: https://doi.org/10.1016/j.cytogfr.2020.05.007. 
72. Lee J, Park C, Kim HJ, Lee YD, Lee ZH, Song YW, et al. Stimulation of osteoclast migration and bone resorption by c-c chemokine ligands 19 and 21. Exp Mol Med [Internet]. Nature Publishing Group; $2017 ; 49$. Available from: http://dx.doi.org/10.1038/emm.2017.100.

73. Van Raemdonck K, Umar S, Palasiewicz K, Volkov S, Volin MV, Arami S, et al. CCL21/CCR7 signaling in macrophages promotes joint inflammation and Th17-mediated osteoclast formation in rheumatoid arthritis. Cell Mol Life Sci [Internet]. Springer International Publishing; 2020;77:1387-99. Available from: https://doi.org/10.1007/s00018-019-03235-w.

74. Jakobs BD, Spannagel L, Purvanov V, Allmen EU, Von, Matti C, Legler DF. Engineering of nanobodies recognizing the human chemokine receptor CCR7. Int J Mol Sci. 2019;20.

75. Cao G, Wang P, Cui Z, Yue X, Chi S, Ma A, et al. An imbalance between blood CD4 + CXCR5 + Foxp3 + Tfr cells and CD4 + CXCR5 + Tfh cells may contribute to the immunopathogenesis of rheumatoid arthritis. Mol Immunol [Internet]. Elsevier; 2020;125:1-8. Available from: https://doi.org/10.1016/j.molimm.2020.06.003.

76. Moschovakis GL, Bubke A, Friedrichsen M, Falk CS, Feederle R, Förster R. T cell specific Cxcr5 deficiency prevents rheumatoid arthritis. Sci Rep. 2017;7:1-13.

77. Armas-González E, Domínguez-Luis MJ, Díaz-Martín A, Arce-Franco M, Castro-Hernández J, Danelon G, et al. Role of CXCL13 and CCL20 in the recruitment of B cells to inflammatory foci in chronic arthritis. Arthritis Res Ther Arthritis Research Therapy. 2018;20:1-12.

78. Yamaguchi A, Nozawa K, Fujishiro M, Kawasaki M, Suzuki F, Takamori K, et al. CC motif chemokine ligand 13 is associated with rheumatoid arthritis pathogenesis. Mod Rheumatol. 2013;23:856-63.

79. Yamaguchi A, Nozawa K, Fujishiro M, Kawasaki M, Takamori K, Ogawa H, et al. Estrogen inhibits apoptosis and promotes CC motif chemokine ligand 13 expression on synovial fibroblasts in rheumatoid arthritis. Immunopharmacol Immunotoxicol. 2012;34:852-7.

80. Quinn SN, Graves SH, Dains-McGahee C, Friedman EM, Hassan H, Witkowski P, et al. Adenylyl cyclase 3/adenylyl cyclase-associated protein 1 (CAP1) complex mediates the anti-migratory effect of forskolin in pancreatic cancer cells. Mol Carcinog. 2017;56:1344-60.

81. Zhang Y, Luan D, Liu Y, Li H, Dong J, Zhang X, et al. Helicid Reverses Lipopolysaccharide-Induced Inflammation and Promotes GDNF Levels in C6 Glioma Cells through Modulation of Prepronociceptin. Chem Biodivers. 2020;17.

82. Zhou W, jie, Wang D dan, Tao J, Tai Y, Zhou Z wei, Wang Z, et al. Deficiency of $\beta$-arrestin2 exacerbates inflammatory arthritis by facilitating plasma cell formation. Acta Pharmacol Sin. 2020;1-12.

83. Wu X, Zhu D, Tian J, Tang X, Guo H, Ma J, et al. Granulocytic Myeloid-Derived Suppressor Cell Exosomal Prostaglandin E2 Ameliorates Collagen-Induced Arthritis by Enhancing IL-10 + B Cells. Front Immunol. 2020;11:1-11.

84. Ajam F, Aghaei M, Mohammadi S, Samiei H, Behnampour N, Memarian A. PD-1 Expression on CD8 + CD28T cells within inflammatory synovium is associated with Relapse: A cohort of Rheumatoid Arthritis. Immunol Lett [Internet]. European Federation of Immunological Societies; 2020;228:76-82. Available from: https://doi.org/10.1016/j.imlet.2020.10.005.

85. Souto-Carneiro MM, Klika KD, Abreu MT, Meyer AP, Saffrich R, Sandhoff R, et al. Effect of Increased Lactate Dehydrogenase A Activity and Aerobic Glycolysis on the Proinflammatory Profile of Autoimmune CD8 + T Cells in Rheumatoid Arthritis. Arthritis Rheumatol. 2020;72:2050-64. 
86. Boutet MA, Courties G, Nerviani A, Le Goff B, Apparailly F, Pitzalis C, et al. Novel insights into macrophage diversity in rheumatoid arthritis synovium. Autoimmun Rev. 2021.

87. Yokota K, Sato K, Miyazaki T, Aizaki Y, Tanaka S, Sekikawa M, et al. Characterization and Function of Tumor Necrosis Factor alpha and Interleukin-6-Induced Osteoclasts in Rheumatoid Arthritis. Arthritis Rheumatol. 2021;0-1.

88. Han J, Li X, Luo X, He J, Huang X, Zhou Q, et al. The mechanisms of hydroxychloroquine in rheumatoid arthritis treatment: Inhibition of dendritic cell functions via Toll like receptor 9 signaling. Biomed Pharmacother. 2020;132.

89. Yabe R, Chung SH, Murayama MA, Kubo S, Shimizu K, Akahori Y, et al. TARM1 contributes to development of arthritis by activating dendritic cells through recognition of collagens. Nat Commun [Internet]. Springer US; 2021;12:1-12. Available from: http://dx.doi.org/10.1038/s41467-020-20307-9.

90. Rivellese F, Nerviani A, Rossi FW, Marone G, Matucci-Cerinic M, de Paulis A, et al. Mast cells in rheumatoid arthritis: friends or foes? Autoimmun Rev [Internet]. Elsevier BV; 2017;16:557-63. Available from: http://dx.doi.org/10.1016/j.autrev.2017.04.001.

91. Okamura Y, Mishima S, Kashiwakura J, ichi, Sasaki-Sakamoto T, Toyoshima S, Kuroda K, et al. The dual regulation of substance P-mediated inflammation via human synovial mast cells in rheumatoid arthritis. Allergol Int [Internet]. Elsevier BV; 2017;66:S9-20. Available from: http://dx.doi.org/10.1016/j.alit.2017.03.002.

92. Rivellese F, Suurmond J, Habets K, Dorjée AL, Ramamoorthi N, Townsend MJ, et al. Ability of interleukin-33and immune complex-triggered activation of human mast cells to down-regulate monocyte-mediated immune responses. Arthritis Rheumatol. 2015;67:2343-53.

93. Suurmond J, Rivellese F, Dorjée AL, Bakker AM, Rombouts YJPC, Rispens T, et al. Toll-like receptor triggering augments activation of human mast cells by anti-citrullinated protein antibodies. Ann Rheum Dis. $2015 ; 74: 1915-23$.

94. Andreev D, Liu M, Kachler K, Llerins Perez M, Kirchner P, Kölle J, et al. Regulatory eosinophils induce the resolution of experimental arthritis and appear in remission state of human rheumatoid arthritis. Ann Rheum Dis. 2020;1-18.

95. Liu L, Zhang Y, Zheng X, Jin L, Xiang N, Zhang M, et al. Eosinophils attenuate arthritis by inducing M2 macrophage polarization via inhibiting the IKB/P38 MAPK signaling pathway. Biochem Biophys Res Commun [Internet]. Elsevier Ltd; 2019;508:894-901. Available from: https://doi.org/10.1016/j.bbrc.2018.12.010.

\section{Tables}

TABLE 1 Basic information of the four datasets

\begin{tabular}{llllll}
\hline GEO & Platform & Organism & Tissue & Normal & RA \\
\hline GSE1919 & GPL91 & Homo sapiens & Synovial tissue & 5 & 5 \\
GSE55235 & GPL96 & Homo sapiens & Synovial tissue & 10 & 10 \\
\hline GSE55457 & GPL96 & Homo sapiens & Synovial tissue & 10 & 13 \\
\hline GSE77298 & GPL570 & Homo sapiens & Synovial tissue & 7 & 16 \\
\hline
\end{tabular}


TABLE 2 Sample numbers of each group

\begin{tabular}{llllll}
\hline Group & GSE1919 & GSE55235 & GSE55457 & GSE77298 & Merged \\
\hline Normal & 5 & 10 & 10 & 7 & 32 \\
RA & 5 & 10 & 13 & 16 & 44 \\
\hline
\end{tabular}

TABLE 3 Statistical results of DEGs in the four datasets

\begin{tabular}{llll}
\hline & ALL & Up-regulated & Down-regulated \\
\hline DEGS & 438 & 275 & 163 \\
\hline
\end{tabular}

TABLE 4 The Top 20 Down-regulated and Up-regulated DEGs in RA 


\begin{tabular}{lccc}
\hline Gene symbol & logFC & P.Value & adj.P.Val \\
\hline Down-regulated & & & \\
PLIN1 & -3.75812 & $1.24 \mathrm{E}-09$ & $4.45 \mathrm{E}-08$ \\
PCK1 & -3.55264 & $5.28 \mathrm{E}-11$ & $3.47 \mathrm{E}-09$ \\
ADH1B & -3.49749 & $6.66 \mathrm{E}-11$ & $4.24 \mathrm{E}-09$ \\
ADIPOQ & -3.37143 & $6.87 \mathrm{E}-09$ & $1.92 \mathrm{E}-07$ \\
APOD & -3.21412 & $2.60 \mathrm{E}-14$ & $6.12 \mathrm{E}-12$ \\
FABP4 & -3.11815 & $3.05 \mathrm{E}-11$ & $2.13 \mathrm{E}-09$ \\
ANGPTL7 & -3.08211 & $2.49 \mathrm{E}-10$ & $1.21 \mathrm{E}-08$ \\
ZBTB16 & -2.6968 & $1.32 \mathrm{E}-13$ & $2.38 \mathrm{E}-11$ \\
ADH1C & -2.5479 & $1.11 \mathrm{E}-09$ & $4.05 \mathrm{E}-08$ \\
RPS4Y1 & -2.45545 & 0.000347 & 0.001991 \\
MAOA & -2.4341 & $2.19 \mathrm{E}-14$ & $5.64 \mathrm{E}-12$ \\
FOSB & -2.43366 & $4.28 \mathrm{E}-05$ & 0.000338 \\
MYOC & -2.38627 & $3.46 \mathrm{E}-10$ & $1.54 \mathrm{E}-08$ \\
FKBP5 & -2.38541 & $2.41 \mathrm{E}-08$ & $5.55 \mathrm{E}-07$ \\
C7 & -2.33321 & $4.26 \mathrm{E}-09$ & $1.30 \mathrm{E}-07$ \\
CYP4B1 & -2.30081 & $2.09 \mathrm{E}-06$ & $2.53 \mathrm{E}-05$ \\
LEP & -2.12959 & $9.81 \mathrm{E}-06$ & $9.59 \mathrm{E}-05$ \\
AKR1B10 & -2.11575 & $1.59 \mathrm{E}-13$ & $2.70 \mathrm{E}-11$ \\
GPD1 & -2.05706 & $4.86 \mathrm{E}-07$ & $7.24 \mathrm{E}-06$ \\
PDK4 & -2.00167 & $7.59 \mathrm{E}-07$ & $1.06 \mathrm{E}-05$ \\
Up-regulated & & & \\
IGJ & 5.440321 & $5.19 \mathrm{E}-18$ & $6.29 \mathrm{E}-15$ \\
CXCL13 & 5.200878 & $1.57 \mathrm{E}-21$ & $1.33 \mathrm{E}-17$ \\
IGLC1 & 5.191091 & $5.53 \mathrm{E}-20$ & $1.17 \mathrm{E}-16$ \\
IGHM & 4.703149 & $1.01 \mathrm{E}-20$ & $2.86 \mathrm{E}-17$ \\
IGLV1-44 & 4.641258 & $3.98 \mathrm{E}-17$ & $3.07 \mathrm{E}-14$ \\
MMP1 & 4.518481 & $8.20 \mathrm{E}-12$ & $7.17 \mathrm{E}-10$ \\
TNFRSF17 & 3.991615 & $1.27 \mathrm{E}-14$ & $3.38 \mathrm{E}-12$ \\
IGKC & 3.799941 & $9.21 \mathrm{E}-17$ & $5.58 \mathrm{E}-14$ \\
ADAMDEC1 & 3.252949 & $1.39 \mathrm{E}-16$ & $7.87 \mathrm{E}-14$ \\
NKG7 & 3.212648 & $2.35 \mathrm{E}-14$ & $5.86 \mathrm{E}-12$ \\
CXCL9 & 3.038077 & $8.34 \mathrm{E}-14$ & $1.57 \mathrm{E}-11$ \\
MMP13 & 2.937127 & $3.34 \mathrm{E}-10$ & $1.51 \mathrm{E}-08$ \\
LRRC15 & 2.903438 & $5.53 \mathrm{E}-21$ & $2.34 \mathrm{E}-17$ \\
LAMP3 & 2.898897 & $2.30 \mathrm{E}-12$ & $2.53 \mathrm{E}-10$ \\
IGHD & 2.85142 & $2.04 \mathrm{E}-12$ & $2.31 \mathrm{E}-10$ \\
CXCL10 & 2.796226 & $5.91 \mathrm{E}-16$ & $2.51 \mathrm{E}-13$ \\
CD52 & 2.746439 & $1.06 \mathrm{E}-14$ & $3.07 \mathrm{E}-12$ \\
GUSBP11 & 2.713471 & $7.64 \mathrm{E}-18$ & $7.20 \mathrm{E}-15$ \\
AQP9 & 2.687603 & $3.49 \mathrm{E}-11$ & $2.41 \mathrm{E}-09$ \\
CCL18 & 2.668925 & $7.54 \mathrm{E}-12$ & $6.87 \mathrm{E}-10$ \\
\hline & & &
\end{tabular}

TABLE 5 GO analysis of RA 


\begin{tabular}{|c|c|c|c|c|}
\hline ID & Description & alue & adjust & eneID \\
\hline \multicolumn{5}{|l|}{$\overline{\mathrm{BP}}$} \\
\hline GO:0007159 & $\begin{array}{l}\text { ukocyte cell-cell } \\
\text { dhesion }\end{array}$ & $\begin{array}{l}2.51 \mathrm{E}- \\
32\end{array}$ & $1.14 \mathrm{E}-$ & $\begin{array}{l}\text { RAC2/CCL5/CD27/BCL6/ITGA4/HLA-DMB/ZBTB16/ } \\
\text { RUNX3/ITGB2/LEF1/PTPRC/TNFSF11/ }\end{array}$ \\
\hline GO:0042110 & T cell activation & $\begin{array}{l}4.25 \mathrm{E}- \\
30\end{array}$ & $\begin{array}{l}9.70 \mathrm{E}- \\
27\end{array}$ & $\begin{array}{l}\text { RAC2/CCL5/CD27/BCL6/CD3D/HLA-DMB/ZBTB16/ } \\
\text { RUNX3/CD2/LEF1/PTPRC }\end{array}$ \\
\hline GO:1903037 & $\begin{array}{l}\text { regulation of } \\
\text { leukocyte cell-cell } \\
\text { adhesion }\end{array}$ & $\begin{array}{l}7.89 \mathrm{E}- \\
27\end{array}$ & $\begin{array}{l}1.20 \mathrm{E}- \\
23\end{array}$ & $\begin{array}{l}\text { CCL5/CD27/BCL6/ITGA4/HLA-DMB/ZBTB16/RUNX3/ } \\
\text { ITGB2/LEF1/PTPRC/TNFSF11/LCK }\end{array}$ \\
\hline GO:0050863 & regulation of $\mathrm{T}$ cell & $1.20 \mathrm{E}-$ & $1.38 \mathrm{E}-$ & RAC2/CCL5/CD27/BCL6/HLA-DMB/ZBTB16/RUNX3/ \\
\hline GO:0030098 & lymphocyte & $1.74 \mathrm{E}-$ & $1.59 \mathrm{E}-$ & CD27/BCL6/DOCK10/CD3D/ITGA4/ZBTB16/RUNX3/ \\
\hline GO:1903039 & $\begin{array}{l}\text { positive regulation of } \\
\text { leukocyte cell-cell } \\
\text { adhesion }\end{array}$ & $\begin{array}{l}2.67 \mathrm{E}- \\
25\end{array}$ & $\begin{array}{l}2.03 E- \\
22\end{array}$ & $\begin{array}{l}\text { CCL5/CD27/BCL6/ITGA4/HLA-DMB/ZBTB16/RUNX3/ } \\
\text { ITGB2/LEF1/PTPRC/TNFSF11/LCK }\end{array}$ \\
\hline GO:0022407 & $\begin{array}{l}\text { regulation of cell-cell } \\
\text { adhesion }\end{array}$ & $\begin{array}{l}1.75 \mathrm{E}- \\
24\end{array}$ & $\begin{array}{l}1.14 \mathrm{E}- \\
21\end{array}$ & $\begin{array}{l}\text { CXCL13/CCL5/CD27/BCL6/ITGA4/HLA-DMB/ZBTB16/ } \\
\text { RUNX3/ITGB2/LEF1/PTPRC/TNFSF11 }\end{array}$ \\
\hline GO:0022409 & positive regulation of & $\begin{array}{l}3.04 \mathrm{E}- \\
24\end{array}$ & $1.73 \mathrm{E}-$ & $\begin{array}{l}\text { CXCL13/CCL5/CD27/BCL6/ITGA4/HLA-DMB/ZBTB16/ } \\
\text { RUNX3/ITGB2/LEF1/PTPR/TNFSF11 }\end{array}$ \\
\hline GO:0050867 & $\begin{array}{l}\text { positive regulation of } \\
\text { cell activation }\end{array}$ & $\begin{array}{l}24 \\
1.19 \mathrm{E}- \\
23\end{array}$ & $\begin{array}{l}21 \\
6.05 E- \\
21\end{array}$ & $\begin{array}{l}\text { IGHM/IGLC1/IGKC/CCL5/TRBC1/CD27/BCL6/ } \\
\text { HLA-DMB/ZBTB16/RUNX3/CD2/ITGB2 }\end{array}$ \\
\hline GO:0002696 & $\begin{array}{l}\text { positive regulation of } \\
\text { leukocyte activation }\end{array}$ & $\begin{array}{l}1.60 \mathrm{E}- \\
23\end{array}$ & $\begin{array}{l}7.29 \mathrm{E}- \\
21\end{array}$ & $\begin{array}{l}\text { IGHM/IGLC1/IGKC/CCL5/TRBC1/CD27/BCL6/HLA- } \\
\text { DMB/ZBTB16/RUNX3/CD2/ITGB2 }\end{array}$ \\
\hline GO:0030217 & $\mathrm{T}$ cell differentiation & $\begin{array}{l}4.87 \mathrm{E}- \\
23\end{array}$ & $\begin{array}{l}2.02 \mathrm{E}- \\
20\end{array}$ & $\begin{array}{l}\text { CD27/BCL6/CD3D/ZBTB16/RUNX3/CD2/LEF1/PTPRC/ } \\
\text { LCK/IL7R/NCKAP1L/IL15 }\end{array}$ \\
\hline GO:0050870 & $\begin{array}{l}\text { positive regulation of } \\
\text { T cell activation }\end{array}$ & $\begin{array}{l}8.99 \mathrm{E}- \\
22\end{array}$ & $\begin{array}{l}3.42 \mathrm{E}- \\
19\end{array}$ & $\begin{array}{l}\text { CCL5/CD27/BCL6/HLA-DMB/ZBTB16/RUNX3/LEF1/ } \\
\text { PTPRC/TNFSF11/LCK/IL7R/NCKAP1L }\end{array}$ \\
\hline \multicolumn{5}{|r|}{ 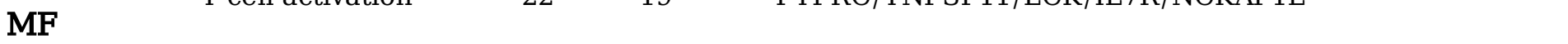 } \\
\hline GO:0140375 & eptor & $3.05 E-$ & $1.94 \mathrm{E}-$ & $\mathrm{A} / \mathrm{CSF} 2 \mathrm{RB} / \mathrm{CCR} 2 /$ \\
\hline GO:0042379 & kine receptor & $\begin{array}{l}13 \\
3.26 \mathrm{E}- \\
11\end{array}$ & $\begin{array}{l}10 \\
0.90 \mathrm{E}-\end{array}$ & $\begin{array}{l}\text { CXCL13/CCL5/CXCL10/STAT1/CXCL9/CCL18/CXCL11/ } \\
\text { CCR2/CXCL6/CCL25/CCL13/CCL19/CCL7/CXCL5/CXCL1 }\end{array}$ \\
\hline GO:0008009 & chen & $\begin{array}{l}3.73 E- \\
11\end{array}$ & $\begin{array}{l}7.90 \mathrm{E}- \\
09\end{array}$ & $\begin{array}{l}\text { CXCL13/CCL5/CXCL10/CXCL9/CCL18/CXCL11/CXCL6/ } \\
\text { CCL25/CCL13/CCL19/CCL7/CXCL5/CXCL1 }\end{array}$ \\
\hline GO:0001664 & $\begin{array}{l}\text { G protein-coupled } \\
\text { receptor binding }\end{array}$ & $\begin{array}{l}5.62 \mathrm{E}- \\
10\end{array}$ & $\begin{array}{l}8.36 \mathrm{E}- \\
08\end{array}$ & $\begin{array}{l}\text { CXCL13/CCL5/CXCL10/STAT1/EDNRB/CXCL9/CCL18/ } \\
\text { SFRP1/CXCL11/CCR2/MYOC/CXCL6 }\end{array}$ \\
\hline GO:0005125 & cytol & $\begin{array}{l}6.58 \mathrm{E}- \\
10\end{array}$ & $\begin{array}{l}8.36 \mathrm{E}- \\
08\end{array}$ & $\begin{array}{l}\text { CXCL13/CCL5/CXCL10/CXCL9/TNFSF11/IL15/CCL18/ } \\
\text { CXCL11/IL32/CXCL6/SPP1/ADIPOQ }\end{array}$ \\
\hline GO:0030546 & $\begin{array}{l}\text { signaling receptor } \\
\text { activator activity }\end{array}$ & $\begin{array}{l}6.48 \mathrm{E}- \\
09\end{array}$ & $\begin{array}{l}6.85 \mathrm{E}- \\
07\end{array}$ & $\begin{array}{l}\text { CXCL13/CCL5/CXCL10/CXCL9/TNFSF11/IL15/CCL18/ } \\
\text { CXCL11/IL32/CXCL6/SPP1/ADIPOQ }\end{array}$ \\
\hline GO:0003823 & antic & $\begin{array}{l}7.63 \mathrm{E}- \\
09\end{array}$ & $\begin{array}{l}6.92 \mathrm{E}- \\
07\end{array}$ & $\begin{array}{l}\text { IGHM/IGLC1/IGLV1-44/IGKC/TRBC1/ITGA4/IGHD/IL7R/ } \\
\text { CD48/HLA-DPB1/TAP1/LILRB4 }\end{array}$ \\
\hline GO:0019955 & cytokine binding & $\begin{array}{l}9.31 \mathrm{E}- \\
09\end{array}$ & $\begin{array}{l}7.39 \mathrm{E}- \\
07\end{array}$ & $\begin{array}{l}\text { IL2RG/CCR5/ITGA4/GBP1/IL10RA/CCR2/IL1R1/CXCR3/ } \\
\text { TGFBR3/ZFP36/CCR1/CXCR4 }\end{array}$ \\
\hline GO:0048018 & $\begin{array}{l}\text { receptor ligand } \\
\text { activity }\end{array}$ & $\begin{array}{l}1.76 \mathrm{E}- \\
08\end{array}$ & $\begin{array}{l}1.24 \mathrm{E}- \\
06\end{array}$ & $\begin{array}{l}\text { CXCL13/CCL5/CXCL10/CXCL9/TNFSF11/IL15/CCL18/ } \\
\text { CXCL11/IL32/CXCL6/SPP1/ADIPOQ }\end{array}$ \\
\hline GO:0019956 & che & $\begin{array}{l}3.11 \mathrm{E}- \\
08\end{array}$ & $\begin{array}{l}1.75 \mathrm{E}- \\
06\end{array}$ & $\begin{array}{l}\text { CCR5/ITGA4/CCR2/CXCR3/ZFP36/CCR1/CXCR4/CCR7/ } \\
\text { CCR6 }\end{array}$ \\
\hline GO:001 & $\begin{array}{l}\mathrm{C}-\mathrm{C} \\
\text { bind }\end{array}$ & $\begin{array}{l}3.18 \mathrm{E}- \\
08\end{array}$ & $\begin{array}{l}1.75 \mathrm{E}- \\
06\end{array}$ & CCR5/CCR2/CXCR3/ZFP36/CCR1/CXCR4/CCR7/CCR6 \\
\hline GO:0004896 & he receptor & $\begin{array}{l}3.31 \mathrm{E}- \\
08\end{array}$ & $\begin{array}{l}1.75 \mathrm{E}- \\
06\end{array}$ & $\begin{array}{l}\text { IL2RG/CCR5/IL7R/IL10RA/CSF2RB/CCR2/IL1R1/CXCR3/ } \\
\text { GFRA2/CCR1/CXCR4/CCR7/GHR/CCR6 }\end{array}$ \\
\hline \multicolumn{5}{|l|}{ CC } \\
\hline GO:C & $\begin{array}{l}\text { exte } \\
\text { plas }\end{array}$ & $\begin{array}{l}3.67 \mathrm{E}- \\
19\end{array}$ & $\begin{array}{l}1.39 \mathrm{E}- \\
16\end{array}$ & ${ }_{2}^{\mathrm{C} / \mathrm{TRBC} 1 / \mathrm{CXCL} 10 / \mathrm{CD} 27 / \mathrm{IL} 2 \mathrm{RG} /}$ \\
\hline GO:0C & ining & $\begin{array}{l}2.85 \mathrm{E}- \\
12\end{array}$ & $\begin{array}{l}5.38 \mathrm{E}- \\
10\end{array}$ & $\begin{array}{l}\text { LRRC15/ADAMDEC1/MXRA5/LAMA2/SFRP1/CTSH/ } \\
\text { ANGPTL7/COL3A1/MYOC/CTSC/COL5A2/ADIPOQ }\end{array}$ \\
\hline GO:0 & tert & $\begin{array}{l}3.96 \mathrm{E}- \\
10\end{array}$ & $\begin{array}{l}4.99 \mathrm{E}- \\
08\end{array}$ & $\begin{array}{l}\text { ITGB2/GGH/NCKAP1L/CTSH/LILRB2/CD300A/CD53/ } \\
\text { CYBA/QPCT/CTSS/CYBB/VAMP8 }\end{array}$ \\
\hline GO:0030665 & $\begin{array}{l}\text { clathrin-c } \\
\text { vesicle } \mathrm{m}\end{array}$ & $\begin{array}{l}6.11 \mathrm{E}- \\
10\end{array}$ & $\begin{array}{l}5.78 \mathrm{E}- \\
08\end{array}$ & $\begin{array}{l}\text { CD3D/EGFR/IL7R/FZD2/HLA-DPB1/CEMIP/WNT5A/ } \\
\text { HLA-DPA1/NRGN/HBEGF/ROR2/VAMP8 }\end{array}$ \\
\hline GO: & ological & $\begin{array}{l}6.83 E- \\
09\end{array}$ & $\begin{array}{l}5.16 \mathrm{E}- \\
07\end{array}$ & $\begin{array}{l}\text { LCK/CRTAM/GZMB/CORO1A/RHOH/LAT/CD53/GZMA/ } \\
\text { CD37/ZAP70 }\end{array}$ \\
\hline GO:0030139 & endocytic vesicle & $\begin{array}{l}1.98 \mathrm{E}- \\
08\end{array}$ & $\begin{array}{l}1.25 \mathrm{E}- \\
06\end{array}$ & $\begin{array}{l}\text { RAC2/EGFR/FZD2/HLA- } \\
\text { DPB1/GSN/TAP1/CORO1A/SYK/CEMIP/CYBA/WNT5A/ } \\
\text { WASL }\end{array}$ \\
\hline GO:0045121 & men & 8E- & $\begin{array}{l}2.6 \\
06\end{array}$ & $\begin{array}{l}\text { EDNRB/EGFR/CD2/ITGB2/PTPRC/CD79A/LCK/CD48/ } \\
\text { ADCY2/CSK/LAT/THY1 }\end{array}$ \\
\hline GO:0098857 & $\begin{array}{l}\text { mem } \\
\text { micr }\end{array}$ & $\begin{array}{l}5.60 \mathrm{E}- \\
08\end{array}$ & $\begin{array}{l}2.65 \mathrm{E}- \\
06\end{array}$ & $\begin{array}{l}\text { EDNRB/EGFR/CD2/ITGB2/PTPRC/CD79A/LCK/CD48/ } \\
\text { ADCY2/CSK/LAT/THY1 }\end{array}$ \\
\hline
\end{tabular}

Page 24/33 


\begin{tabular}{lllll} 
GO:0098589 & membrane region & $1.18 \mathrm{E}-$ & $4.96 \mathrm{E}-$ & EDNRB/EGFR/CD2/ITGB2/PTPRC/CD79A/LCK/CD48/ \\
& & 07 & 06 & ADCY2/CSK/LAT/THY1 \\
GO:0030662 & coated vesicle & $4.62 \mathrm{E}-$ & $1.75 \mathrm{E}-$ & CD3D/EGFR/IL7R/FZD2/HLA-DPB1/CEMIP/WNT5A/ \\
& membrane & 07 & 05 & HLA-DPA1/NRGN/HBEGF/ROR2/VAMP8 \\
GO:0030666 & $\begin{array}{l}\text { endocytic vesicle } \\
\text { membrane }\end{array}$ & $5.20 \mathrm{E}-$ & $1.79 \mathrm{E}-$ & RAC2/FZD2/HLA- \\
& 07 & 05 & $\begin{array}{l}\text { DPB1/TAP1/CORO1A/CYBA/WNT5A/WASL/HLA- } \\
\text { DPA1/CYBB/HBEGF/ROR2 }\end{array}$ \\
GO:0042613 & $\begin{array}{l}\text { MHC class II protein } \\
\text { complex }\end{array}$ & $\begin{array}{l}6.31 \mathrm{E}- \\
07\end{array}$ & $\begin{array}{l}1.99 \mathrm{E}- \\
05\end{array}$ & $\begin{array}{l}\text { HLA-DOB/HLA-DMB/HLA-DMA/HLA-DPB1/HLA- } \\
\text { DPA1/HLA-DRB4 }\end{array}$ \\
\hline
\end{tabular}

BP: Biological Process CC: Cellular Component, MF: Molecular Function

\section{Figures}

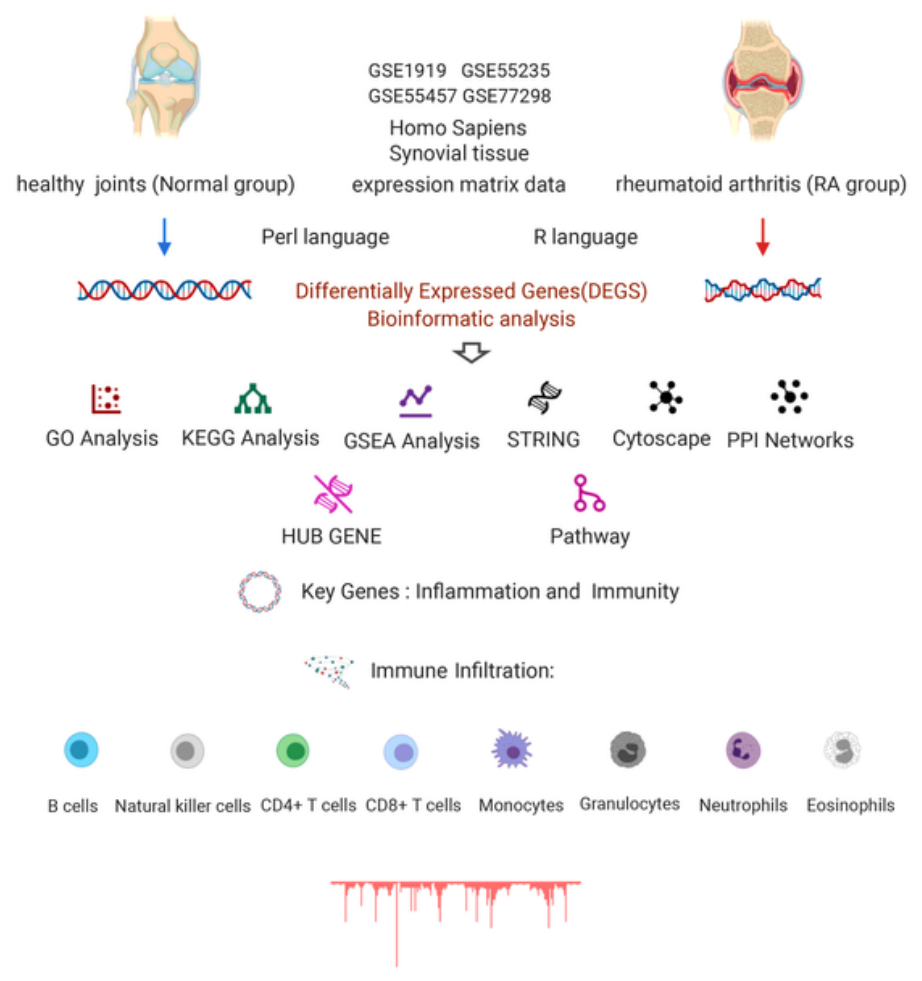

Figure 1

Schematic of the experimental strategy used to identify the hub gene between Rheumatoid arthritis(RA) group and Normal group, Raw data processing using Perl and R language, and identifying and screening differentially expressed genes applying $R$ software limma packages. We assess DEGs' functional and pathway enrichment using GO Analysis, KEGG Pathway Enrichment Analysis, and GSEA, discovering the protein-protein interaction network using the STRING database and Cytoscape software. GOplot obtained hub genes associated with inflammation and immunity, and the CIBERSORT algorithm got infiltrative immunity in RA. 
a

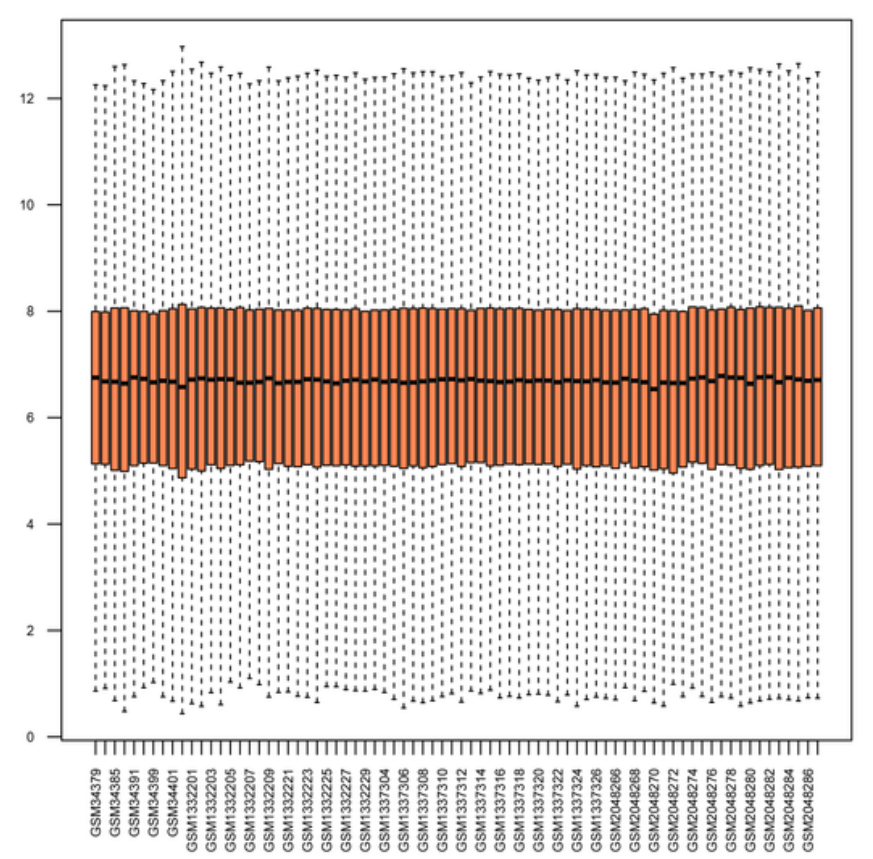

b

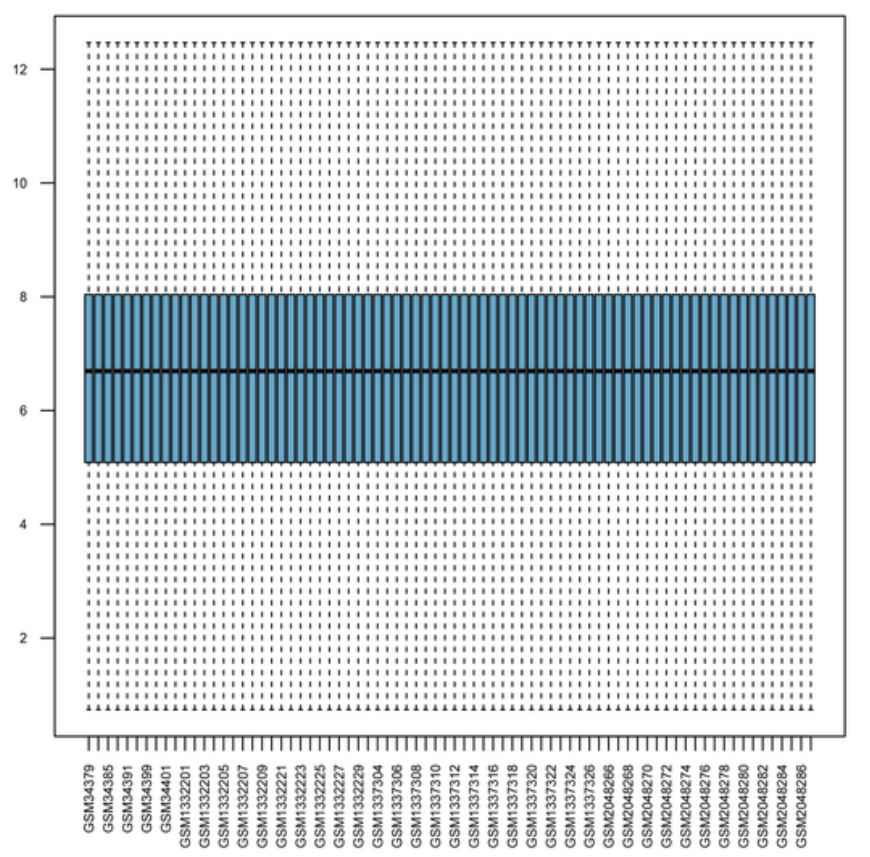

\section{Figure 2}

The boxplots for microarray data before(a) and after(b) normalization.

a

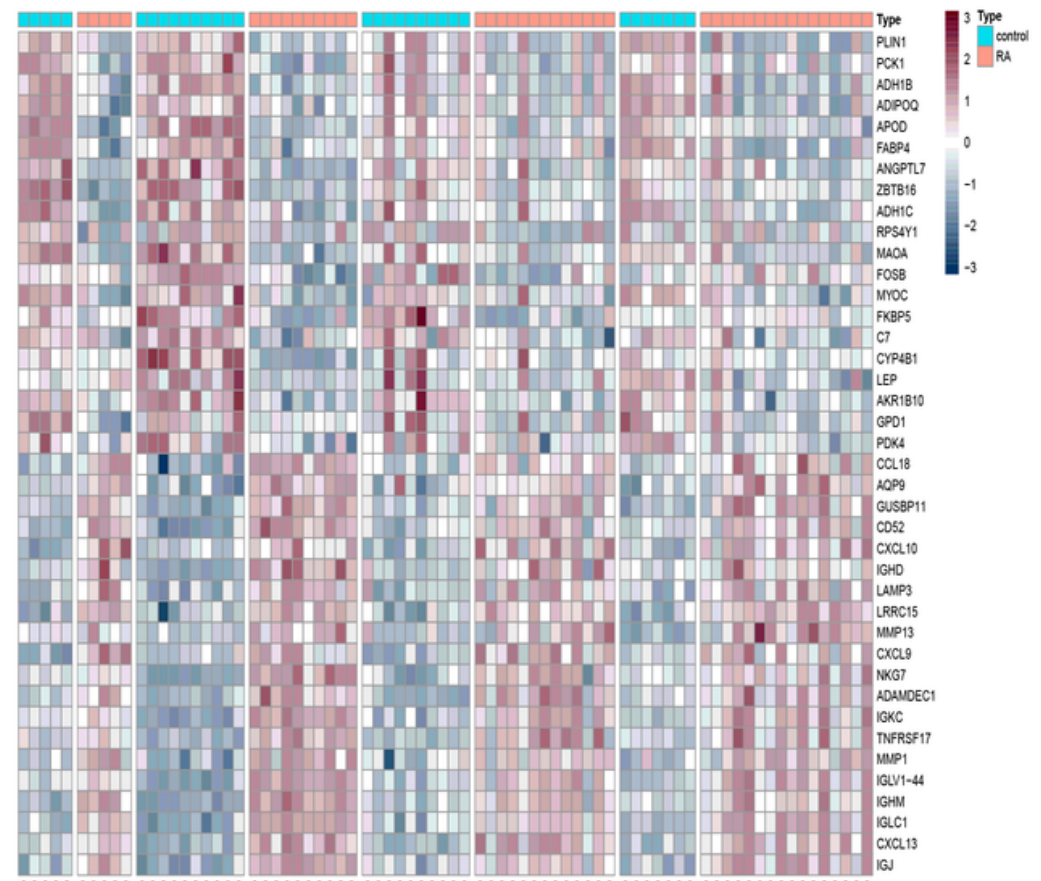

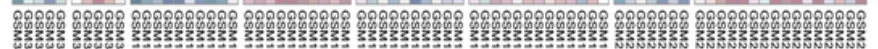

b

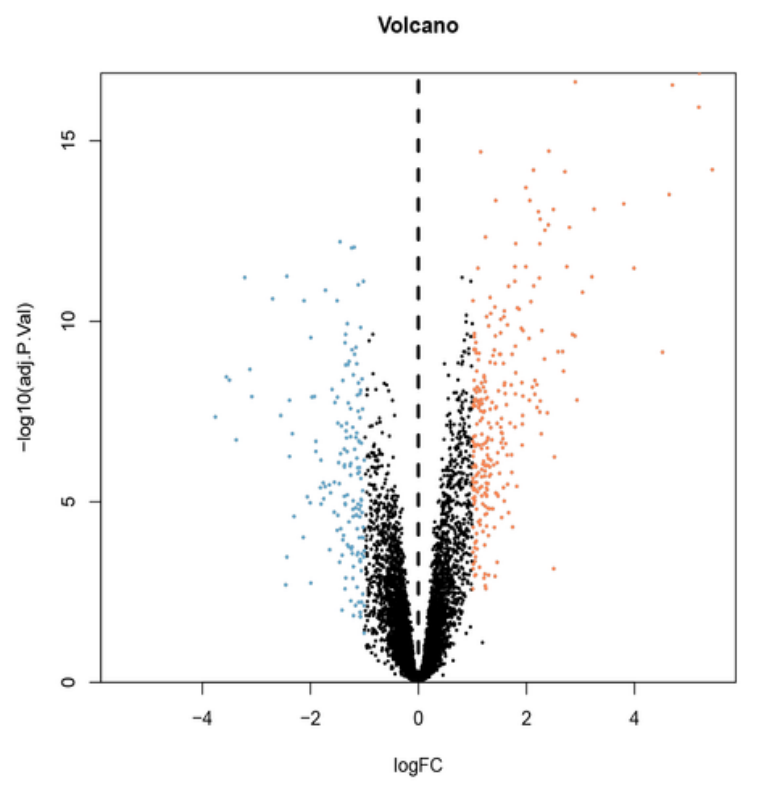




\section{Figure 3}

(a) Heatmap for the top 20 temporal genes. (b) Volcano plot for genes between the control and RA group.Red plots represent upregulated genes with $|\log F C|>1$ and $p<.05$.group.blue plots represent downregulated genes with $|\log \mathrm{FC}|<1$ and $\mathrm{p}<.05$.black plots represent the remaining genes with no significant difference.

a
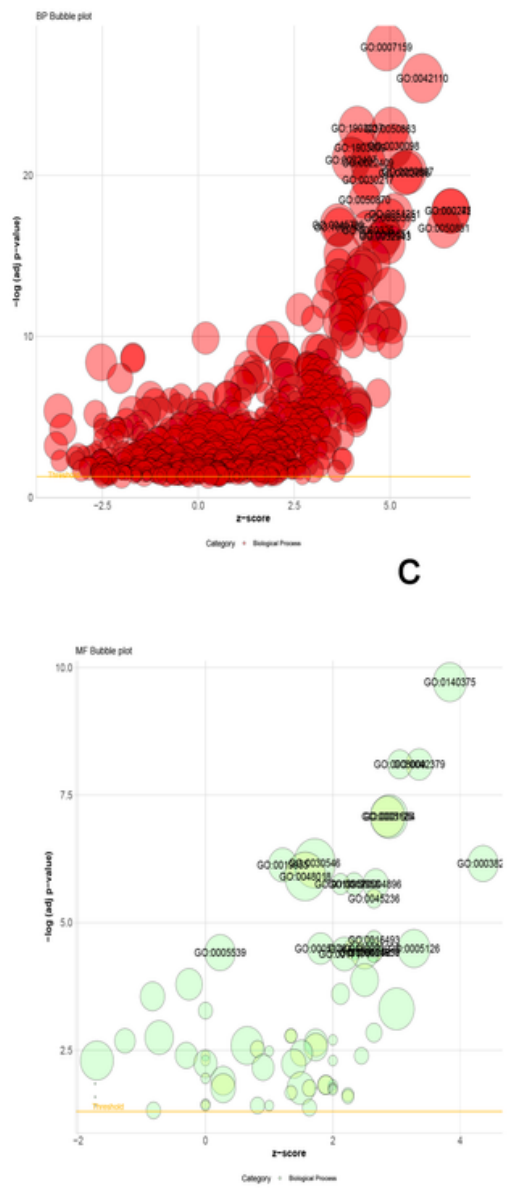
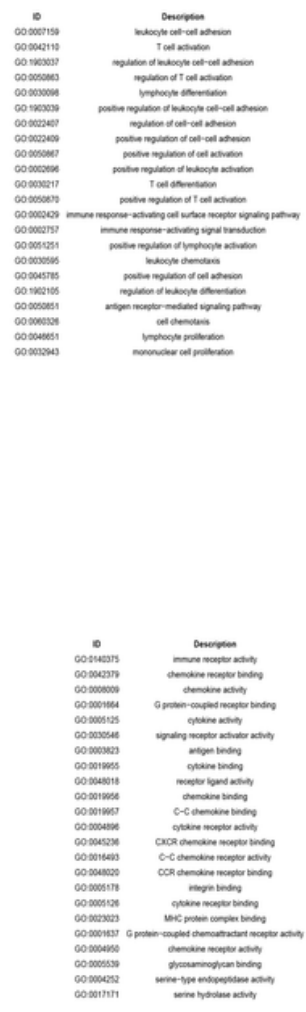

b
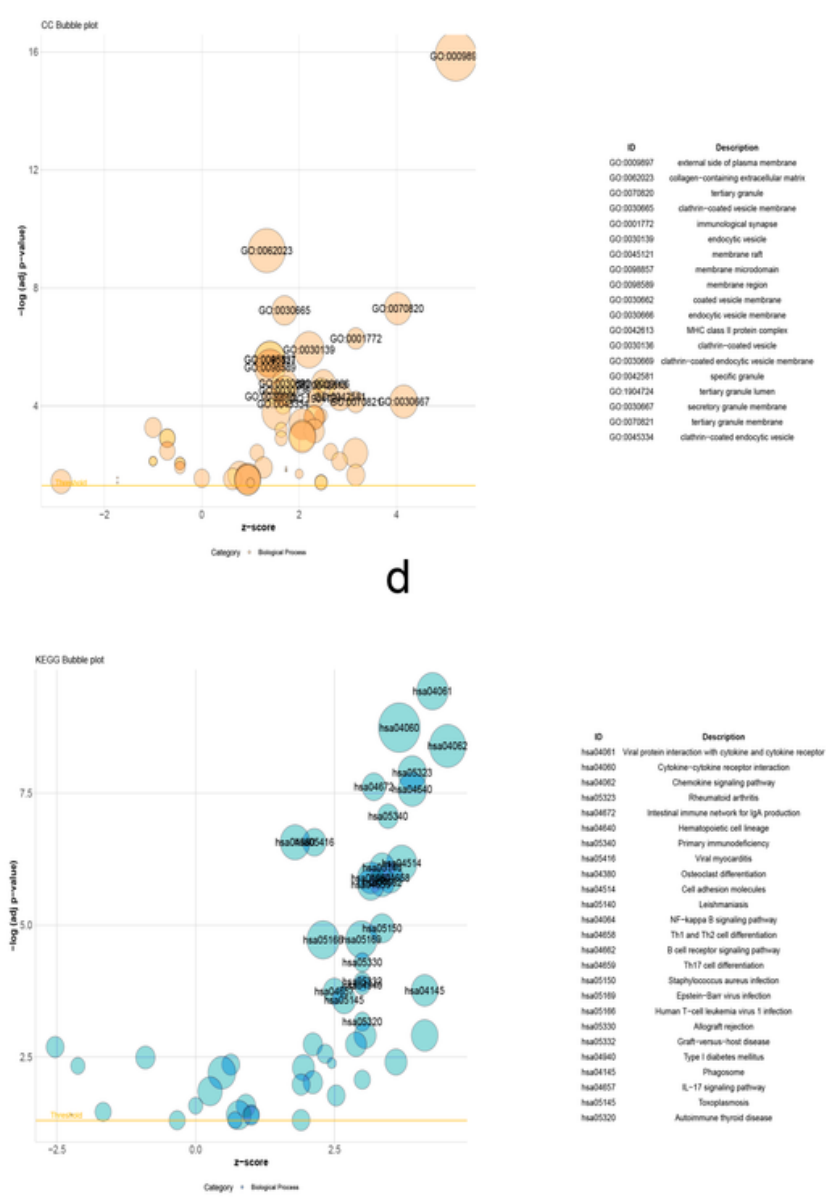

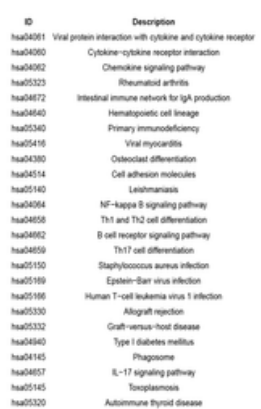

\section{Figure 4}

Gene Ontology (GO) enrichment analysis (a) biological process (BP), (b) cellular component (CC) and (c) molecular function (MF) ) for the DEGs in RA. the circles are labeled with the term ID, a table connecting the IDs and terms is displayed on the right side. A threshold for the labeling is set based on the negative logarithm of the adjusted p-value <.05. (d) Kyoto Encyclopedia of Genes and Genomes(KEGG)terms enrichment analysis results for RA's DEGs. 

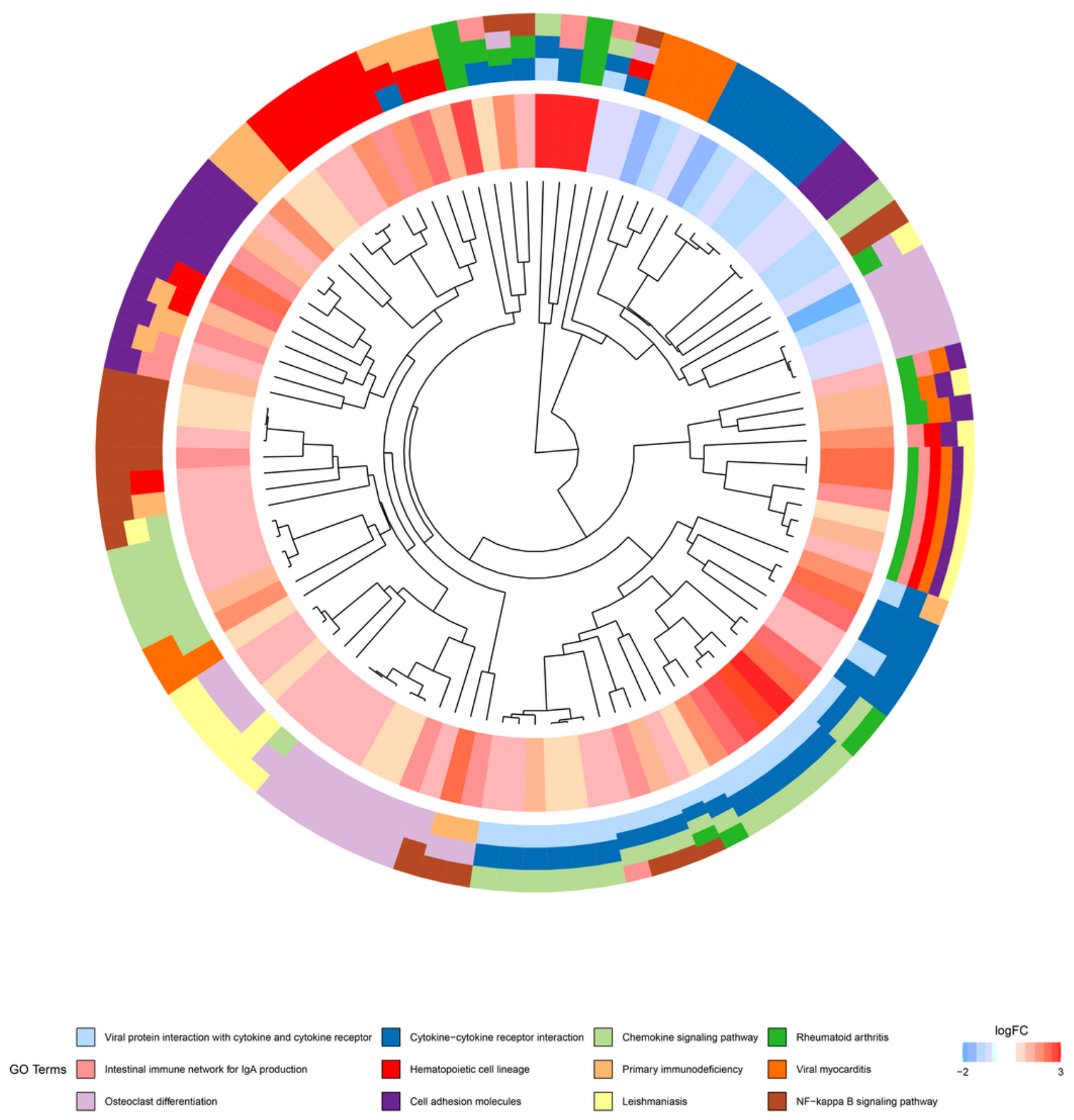

\section{Figure 5}

The KEGG enrichment analysis's GOcluster plot. The first ring next to the dendrogram represents the logFC of the genes, the clustering tree leaves. The next ring depicts the terms assigned to the genes. 
a

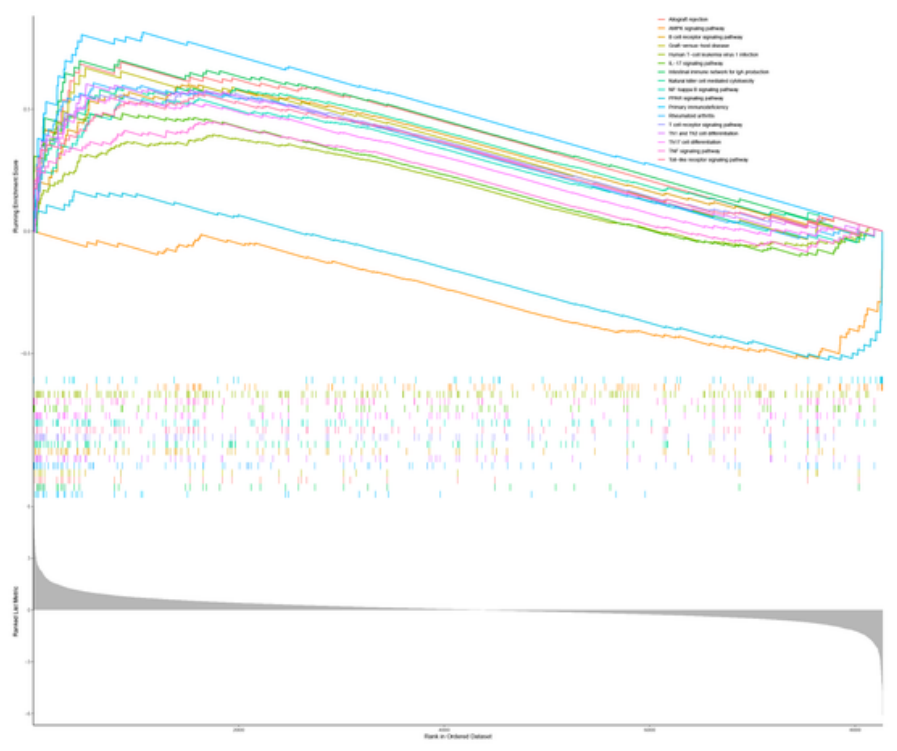

C

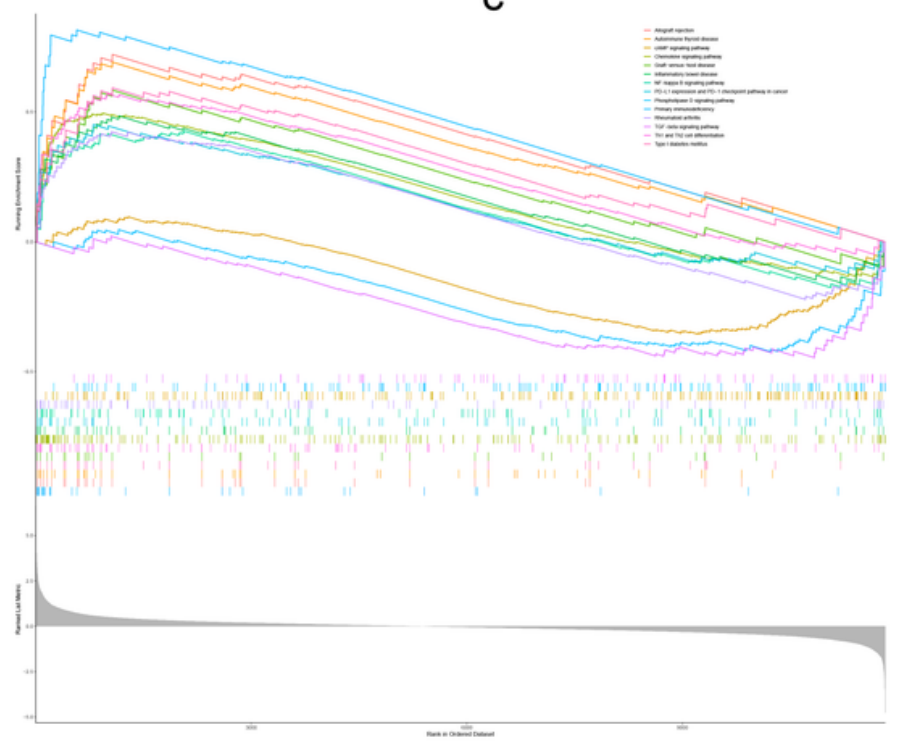

b

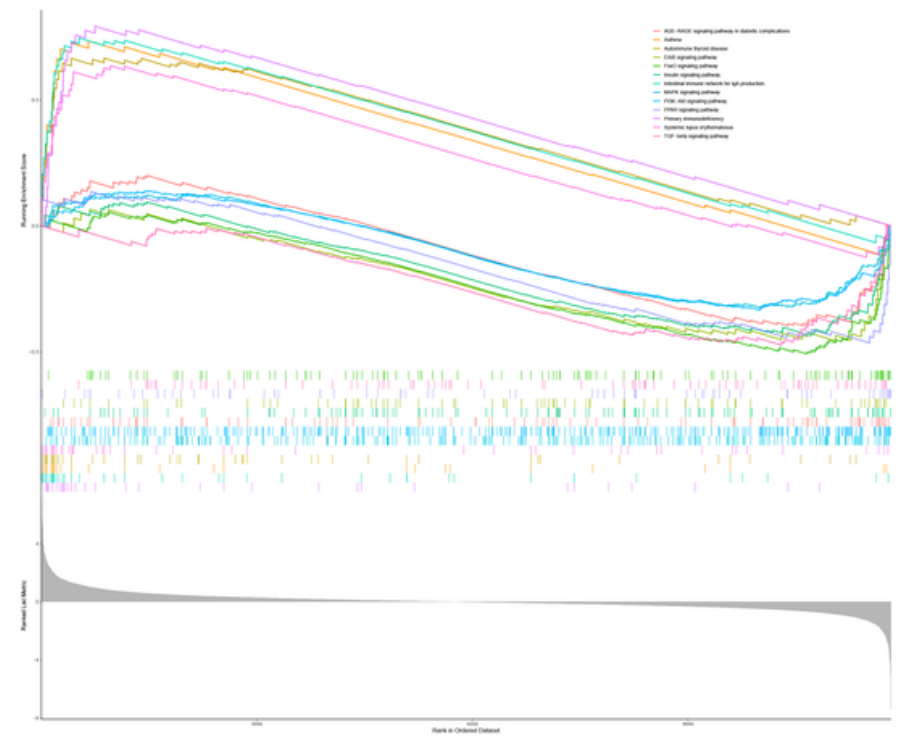

d

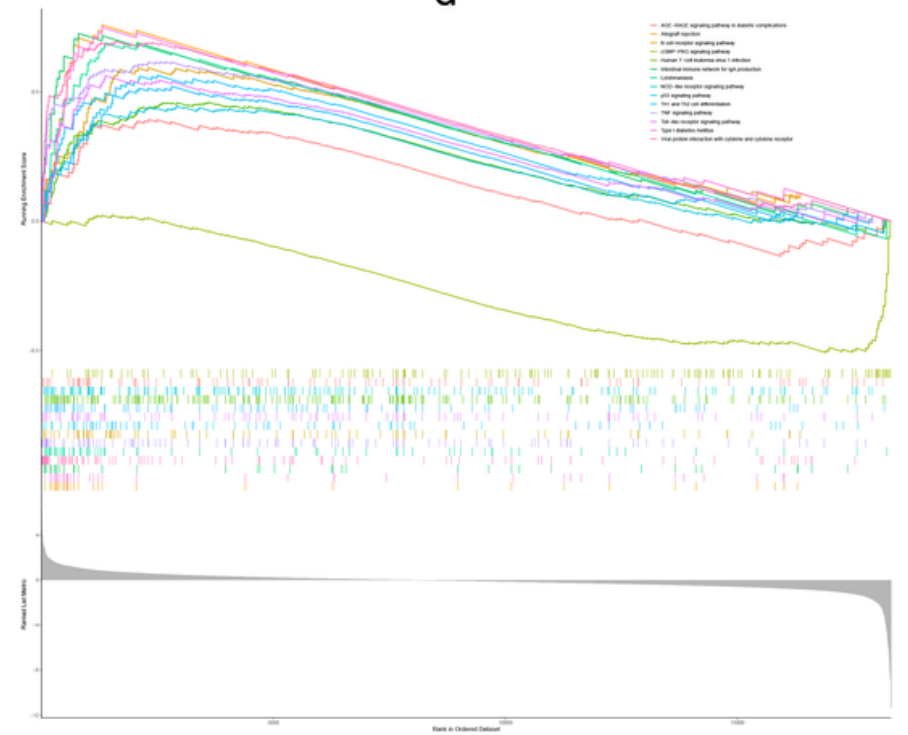

\section{Figure 6}

Gene-set enrichment analysis(GSEA)analysis in RA 


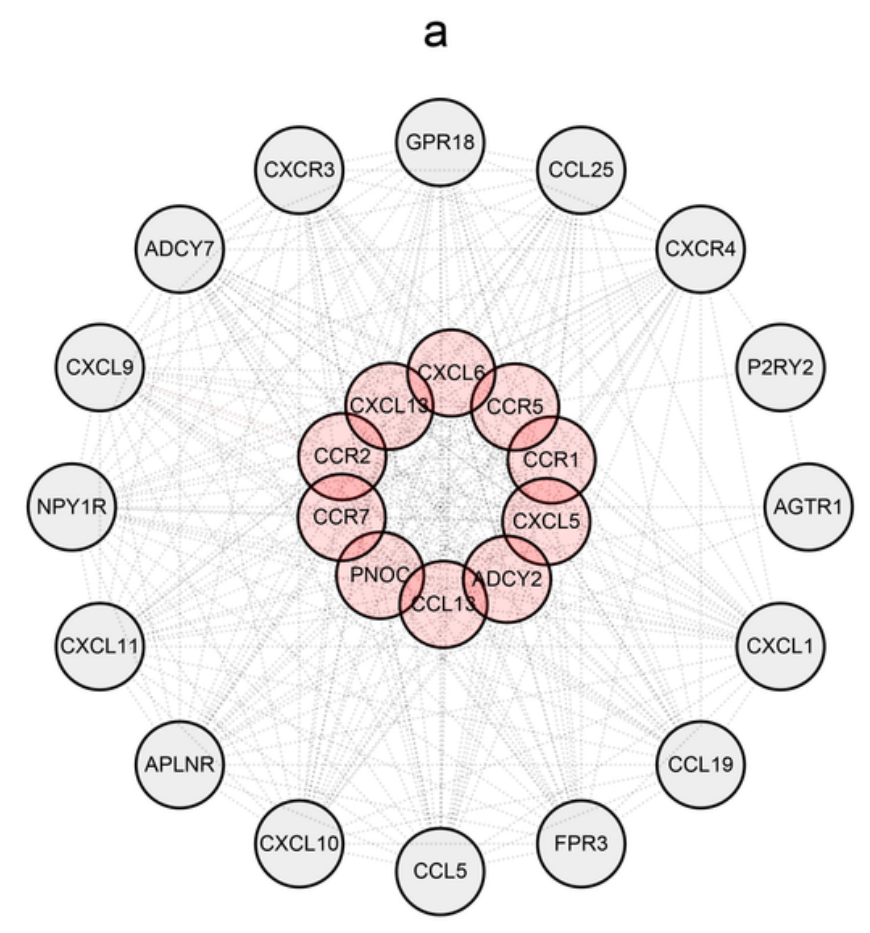

\section{b}

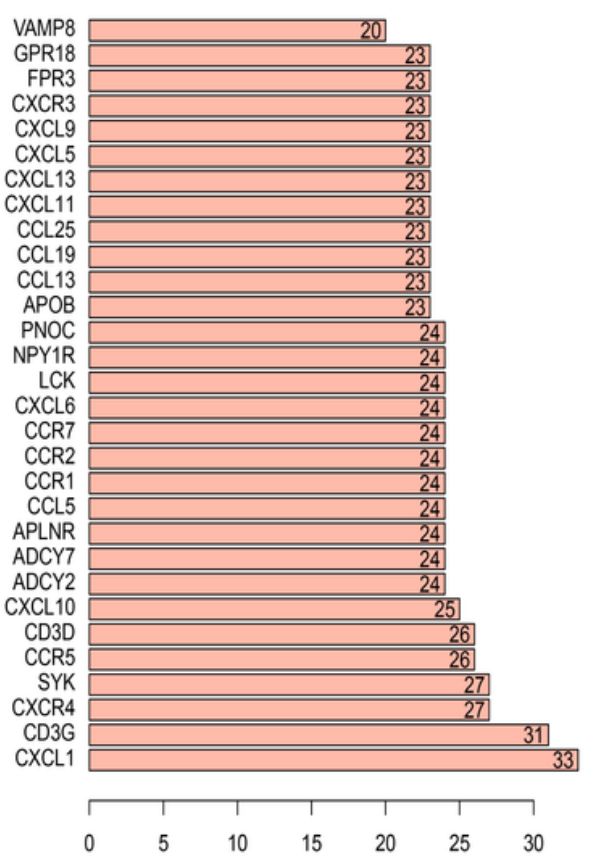

Figure 7

(a) Top 10 hub genes in RA using MCC algorithm. (b) Bar-plot of top 30 core genes with the most weight in RA. 
a

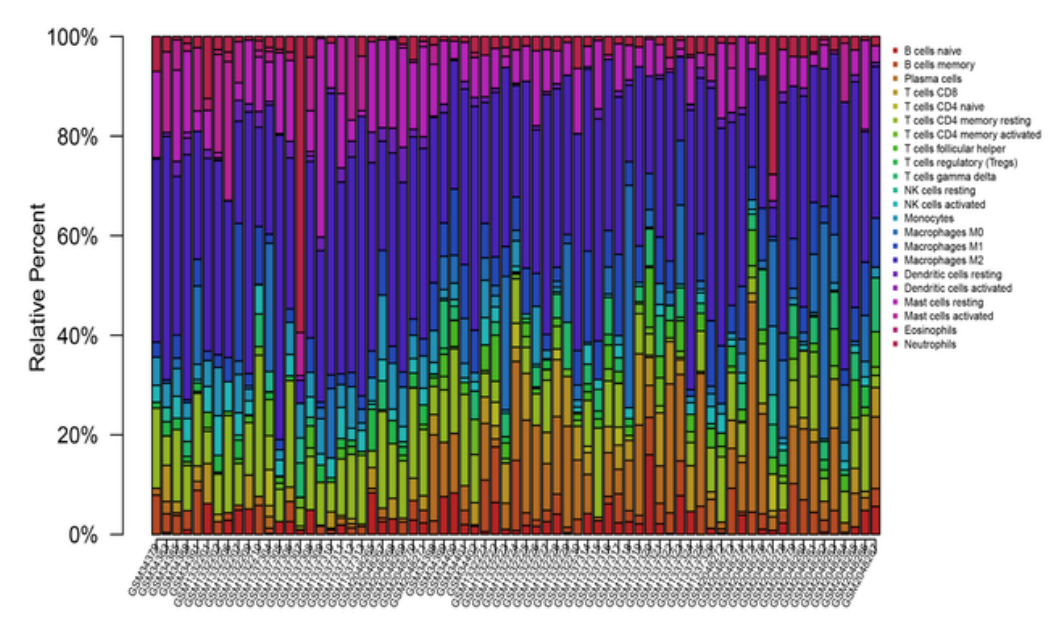

C

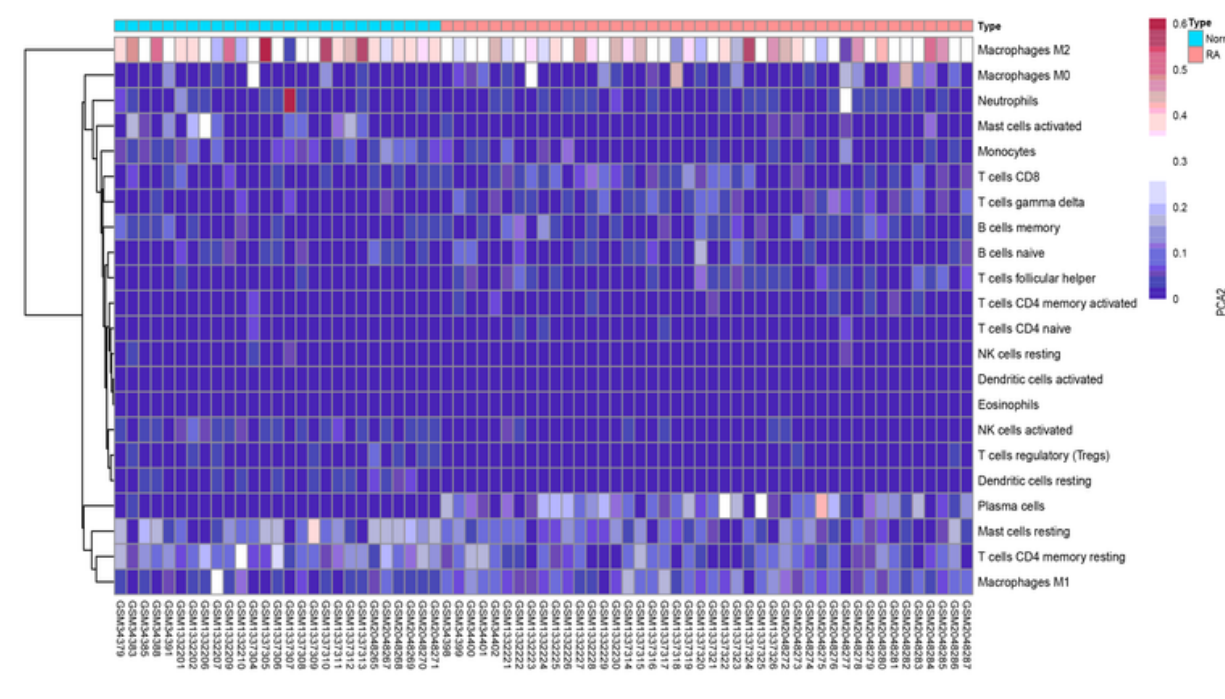

b

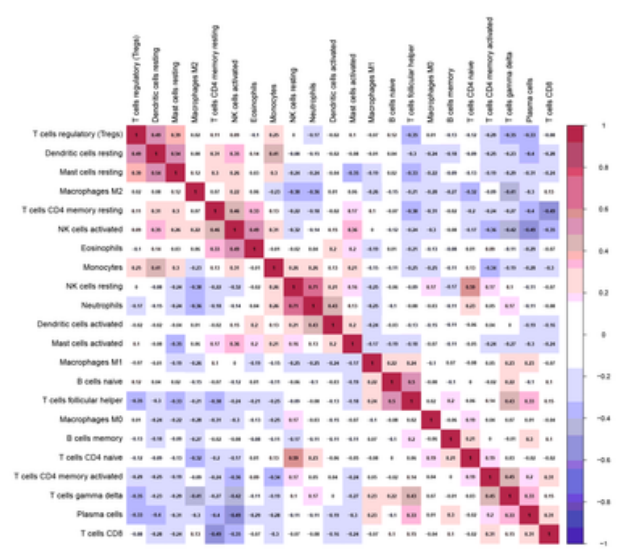

d

\section{Figure 8}

Results of CIBERSORT analysis. (a)The relative percentage of 22 subpopulations of immune cells in 71 samples from four datasets. (b)The correlation heat map graph is shown by the rate of correlation between individual immune cells. (c) Distribution of 22 immune cells in the gene matrix of 71 data samples. Immune infiltration expression of each immune cell in these samples: red indicates higher expression, and green shows lower expression. (d) Principal components analyses(PCA) were performed on all samples. The first two principal components, which explain most of the data variation, 


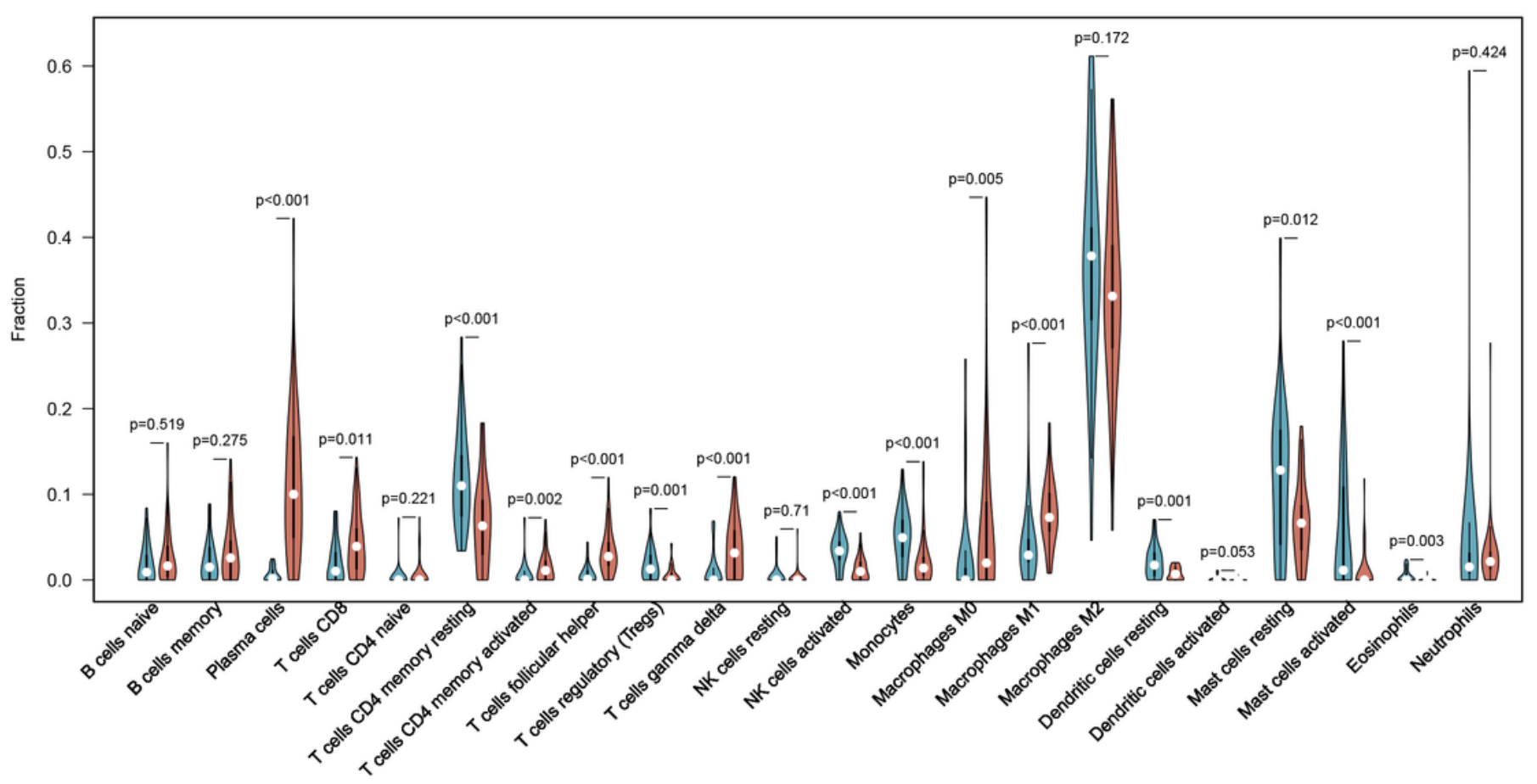

Figure 9

Immune infiltration between RA and normal groups. The violin plot groups of the two immune cell ratios. The blue spindle fraction on the left represents the normal group, and the red spindle fraction on the right represents the RA group. 


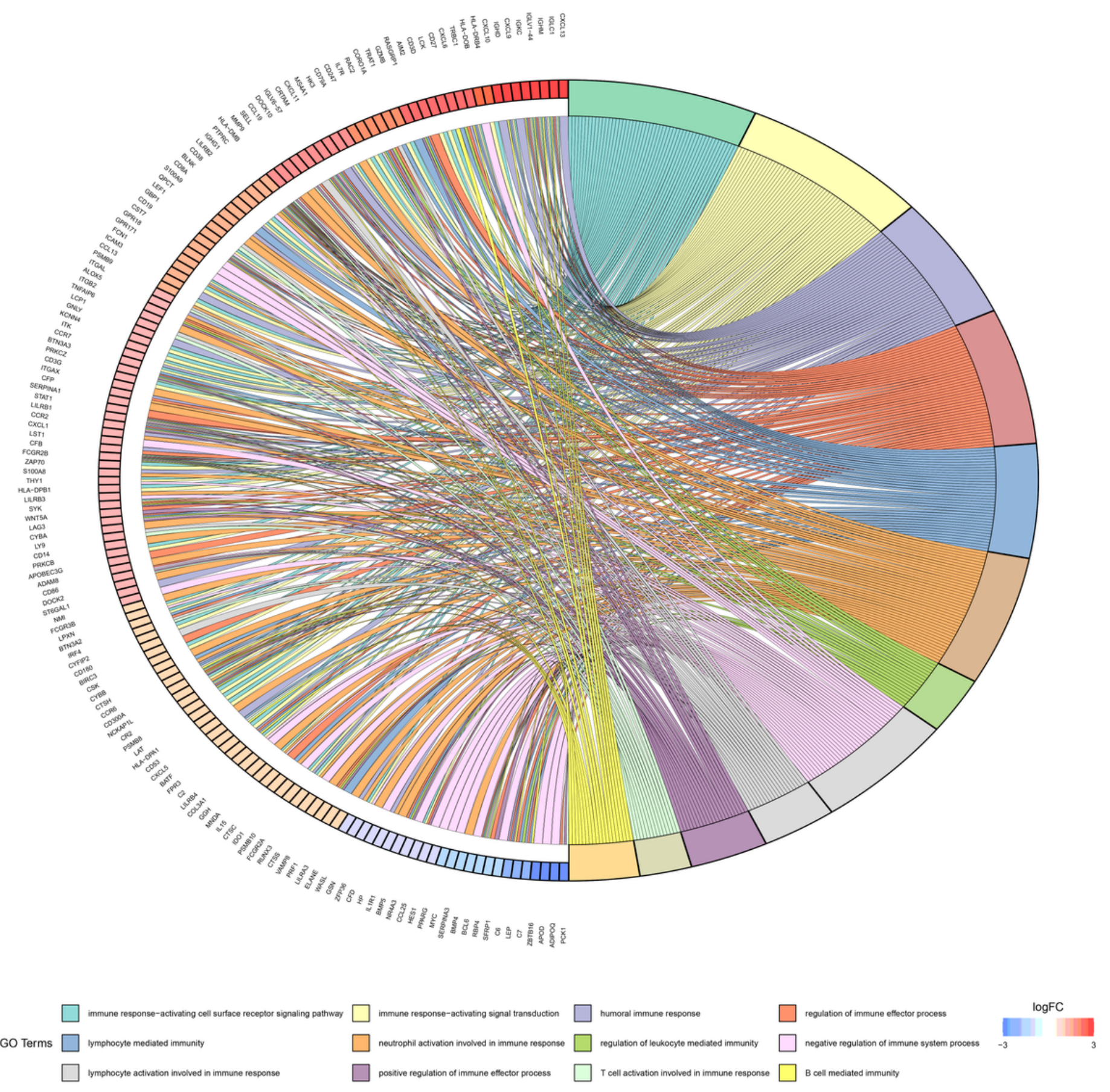

Figure 10

GOChord plot for Inflammatory immune-related HUB genes 